\title{
A Map of Functional Synaptic Connectivity in the Mouse Anteroventral Cochlear Nucleus
}

\author{
Luke Campagnola ${ }^{1,2}$ and Paul B. Manis ${ }^{1,2,3}$ \\ ${ }^{1}$ Department of Otolaryngology/Head and Neck Surgery, ${ }^{2}$ Curriculum in Neurobiology, and ${ }^{3}$ Department of Cell Biology and Physiology, The University of \\ North Carolina at Chapel Hill, Chapel Hill, North Carolina 27599-7070
}

\begin{abstract}
The cochlear nuclei are the first central processors of auditory information and provide inputs to all the major brainstem and midbrain auditory nuclei. Although the local circuits within the cochlear nuclei are understood at a cellular level, the spatial patterns of connectivity and the connection strengths in these circuits have been less well characterized. We have applied a novel, quantitative approach to mapping local circuits projecting to cells in the mouse anteroventral cochlear nucleus (AVCN) using laser-scanning photostimulation and glutamate uncaging. The amplitude and kinetics of individual evoked synaptic events were measured to reveal the patterns and strengths of synaptic connections. We found that the two major excitatory projection cell classes, the bushy and T-stellate cells, receive a spatially broad inhibition from D-stellate cells in the AVCN, and a spatially confined inhibition from the tuberculoventral cells of the dorsal cochlear nucleus. Furthermore, T-stellate cells integrate D-stellate inhibition from an area that spans twice the frequency range of that integrated by bushy cells. A subset of both bushy and T-stellate cells receives inhibition from an unidentified cell population at the dorsal-medial boundary of the AVCN. A smaller subset of cells receives local excitation from within the AVCN. Our results show that inhibitory circuits can have target-specific patterns of spatial convergence, synaptic strength, and receptor kinetics, resulting in different spectral and temporal processing capabilities.
\end{abstract}

Key words: brain mapping; glutamate uncaging; inhibitory function; laser photostimulation; local circuits; topography

\section{Introduction}

The synaptic connectivity of neural networks is an essential determinant of their role in information processing. Detailed analyses of network connection patterns, including their spatial organization, synaptic strength, and kinetics, are a prerequisite for the construction of biologically relevant models used to explore hypotheses about neural integration. Local circuits can be more readily understood in sensory systems than in more centrally located structures because the activity patterns of the principal inputs to sensory nuclei are well defined. The anteroventral cochlear nucleus (AVCN) receives direct input from the auditory nerve and is particularly amenable to this kind of analysis. Its intrinsic circuitry is relatively simple, with only a few distinct types of local inhibitory interneurons and relatively sparse intrinsic excitatory connections. Models of cellular excitability (Rothman and Manis, 2003b), synaptic kinetics (Raman and Trussell, 1992; Xie and Manis, 2013), and

\footnotetext{
Received Nov. 4, 2013; revised Dec. 17, 2013; accepted Dec. $22,2013$.

Author contributions: L.C. and P.B.M. designed research; L.C. performed research; L.C. and P.B.M. contributed unpublished reagents/analytic tools; L.C. and P.B.M. analyzed data; L.C. and P.B.M. wrote the paper.

This work was supported by National Institute on Deafness and Other Communication Disorders Grant R01DC004551 (to P.B.M.) and National Research Service Award 5F31DC10320 (to L.C.). We thank M. Kratz for assistance with software and hardware development, and comments on the manuscript; $H$. $O^{\prime}$ Donohue for experimental and organizational support; and M. Muniak for assistance with his cochleotopic atlas.

The authors declare no competing financial interests.

Correspondence should be addressed to Dr. Paul B. Manis, G127 Physician's Office Building, CB\#7070, 170 Manning Drive, Chapel Hill, NC 27599-7070. E-mail: pmanis@med.unc.edu.

DOI:10.1523/JNEUROSCI.4669-13.2014

Copyright $\odot 2014$ the authors $\quad 0270-6474 / 14 / 342214-17 \$ 15.00 / 0$
}

the auditory nerve (Zilany et al., 2009) are available, making the AVCN suitable for quantitative analysis and modeling.

The AVCN is composed of three primary cell types (Fig. 1A). Bushy cells and T-stellate cells are the AVCN's excitatory output neurons, whereas D-stellate cells are glycinergic (Doucet et al., 1999; Doucet and Ryugo, 2006). Bushy and T-stellate cells form two parallel pathways that enhance different features of their auditory nerve input (Blackburn and Sachs, 1989; Xie and Manis, 2013). Bushy cells preserve the fine temporal structure of their inputs and project to the superior olivary complex, whereas T-stellate cells encode the amplitude envelope of sound on a slower timescale and project to the inferior colliculus (Blackburn and Sachs, 1990; Frisina et al., 1990; Joris et al., 1994; Shofner, 1999; Cant and Benson, 2003). Both cell types lie within the terminal axonal fields of the inhibitory D-stellate cells, which are a strong candidate to provide broadly tuned inhibition. A separate inhibitory input to the AVCN comes from narrowly tuned tuberculoventral neurons in the dorsal cochlear nucleus (DCN; Young and Voigt, 1982; Wickesberg and Oertel, 1990; Ostapoff et al., 1999; Muniak and Ryugo, 2013). Together, these cell types form the basic feedforward circuit of the AVCN.

Prior studies have characterized the connectivity of local circuits in the AVCN. However, systematic and quantitative spatial measurements are required to facilitate computational modeling and to elucidate the functional role of these circuits. We have applied a novel, quantitative approach to mapping circuits in the AVCN using laser-scanning photostimulation in brain slices. We used glutamate uncaging to systematically stimulate presynaptic cells, then measured the amplitude and kinetics of the evoked synaptic events to generate a detailed description of connection 


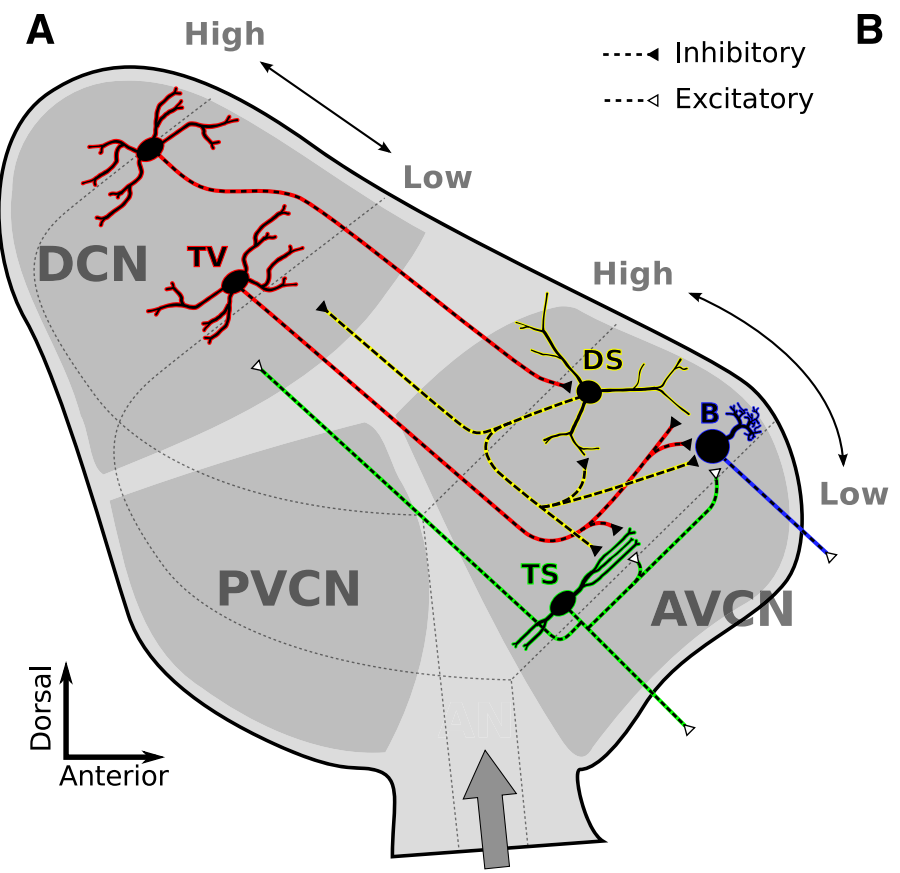

B
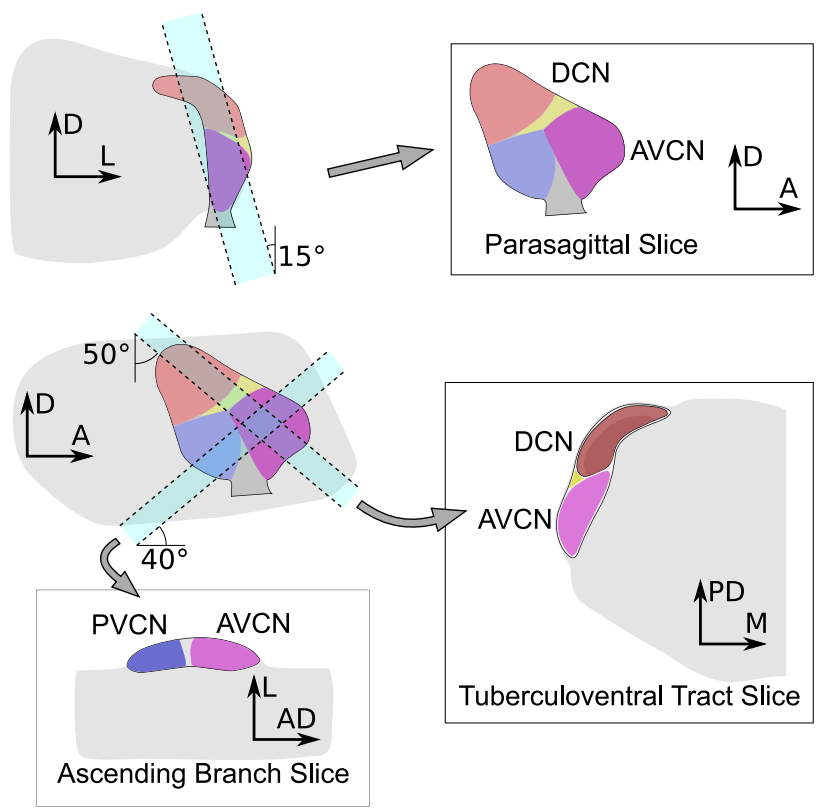

C
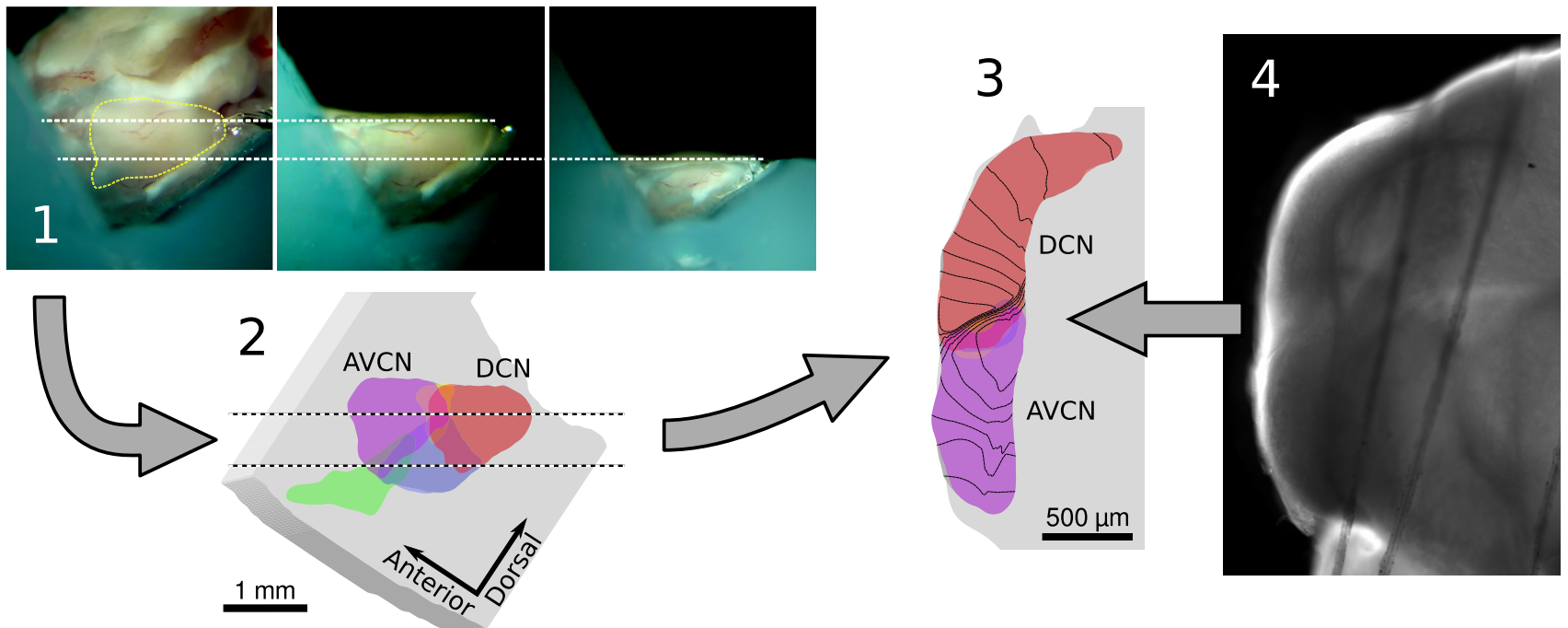

Figure 1. Schematic of putative AVCN circuitry and the slice planes used in this study. A, Sagittal view of the cochlear nuclei showing a subset of cell types and circuitry relevant to the AVCN. Auditory nerve (AN) fibers enter the ventral cochlear nucleus at the ventral edge, then bifurcate into an "ascending" branch that innervates the AVCN, and a "descending" branch that innervates the PVCN and DCN. AN fibers are organized tonotopically into sheets of similar frequency, with low frequencies near the ventral-lateral edge and high frequencies at the dorsal-medial edge. Bushy (B) and T-stellate (TS) cells are the primary excitatory output neurons of the AVCN and project ventrally to the trapezoid body. Both cell types integrate AN input from a narrow range of frequencies. D-stellate (DS) and tuberculoventral (TV) cells are inhibitory interneurons. TV cells project to bushy and T-stellate cells with a precise tonotopic registration. DS cells integrate from a wide range of AN fiber frequencies and have extensive axonal branching in the VCN and DCN. However, their postsynaptic targets are unknown, although they are believed to include both bushy and T-stellate cells. Some TS cells also have sparse local axon collaterals believed to synapse at least onto other T-stellate cells. Whether either of the inhibitory interneurons are the targets of any local projections is unknown. B, Schematics showing the orientation of cuts that produce the slice planes used in this study. Each slice plane was selected to retain specific sets of connections within the nuclei, as described in Materials and Methods. C, Schematic showing the process of registering slices with the anatomical and tonotopic atlases. Photos of the slicing procedure (1) were used to mark the location of the slice on a 3D atlas (2). The atlas was digitally sliced to generate an image of the expected slice anatomy (3). The atlas was also combined with a tonotopic atlas to estimate the center frequency of auditory nerve input across different regions of the slice; example isofrequency curves are drawn over the atlas slice image. Finally, images of the brain slice (4) were scaled and aligned with images of the atlas slice. AD, Anterodorsal; PD, posterodorsal; $D$, dorsal; $A$, anterior; $M$, medial; L, lateral.

patterns and associated synaptic properties. We coupled this approach with a 3D reconstruction of the locations of recorded cells onto a standard atlas (Muniak et al., 2013), which allowed us to estimate the tonotopic relationships between recorded and photostimulated neurons. We found that the majority of cells receive inhibitory input from both D-stellate and tuberculoventral cells. Additionally, small subsets of cells receive inhibitory input from an unidentified cell population at the dorsal-medial boundary of the AVCN, or excitatory input from within the AVCN.

\section{Materials and Methods}

Dissection and slicing. CBA/CaJ mice (Jackson Laboratory) from inhouse colonies, $13-33 \mathrm{~d}$ old (mean age, $23 \pm 5 \mathrm{~d} ; n=50$ ), of either sex were used for all electrophysiological recordings. All experimental pro- 
cedures were approved by the Institutional Animal Care and Use Committee at the University of North Carolina at Chapel Hill. Mice were anesthetized with ketamine $(100 \mathrm{mg} / \mathrm{kg}$, i.p.) and xylazine $(10 \mathrm{mg} / \mathrm{kg}$, i.p.), and then decapitated. The brain was removed and immersed in prewarmed $\left(34^{\circ} \mathrm{C}\right)$ dissection buffer containing the following (in $\mathrm{mm}$ ): $135 \mathrm{~N}$-methyl-D-glucamine (NMDG), $135 \mathrm{HCl}, 1.75 \mathrm{KCl}, 1.25 \mathrm{KH}_{2} \mathrm{PO}_{4}$, $25 \mathrm{NaHCO}_{3}, 10$ glucose, 3 myo-inositol, 2 sodium pyruvate, 0.4 ascorbic acid, $1.5 \mathrm{MgSO}_{4}$, and $2 \mathrm{CaCl}_{2}$, gassed with $95 \% \mathrm{O}_{2}$ and $5 \% \mathrm{CO}_{2}$ to a pH of 7.4. This dissection buffer is based on an NMDG solution proposed by Tanaka et al. (2008) to improve slice viability, but also includes myoinositol, sodium pyruvate, and ascorbic acid. It also lacks choline chloride because the high concentration of $\mathrm{HCl}$ used to set the $\mathrm{pH}$ provided more than sufficient $\mathrm{Cl}^{-}$. A block of brainstem including the cochlear nuclei was dissected and attached to an agar block with cyanoacrylate glue, and placed on a small gimbal in an oscillating tissue slicer (VT 1200S, Leica). The block was then oriented with the gimbal and cut to yield a single section, typically $350-600 \mu \mathrm{m}$ thick.

Each block was cut in one of three planes of section chosen to preserve or emphasize specific aspects of the nucleus circuitry (Fig. 1B). "Parasagittal" slices were cut in a nearly sagittal plane, with the dorsal end tilted $\sim 20^{\circ}$ medial to the sagittal plane. When cutting parasagittal slices, thin slices were shaved from the lateral surfaces of the DCN and ventral cochlear nucleus $(\mathrm{VCN})$ to remove the molecular and granule cell layers before cutting the final slice. Slices in this orientation were typically cut thicker $(500-600 \mu \mathrm{m})$ to help preserve connections between the deep DCN and AVCN. "Ascending branch" slices were cut approximately parallel to the ascending branches of auditory nerve fibers (which run posteroventral at the nerve root to anterodorsal at the opposite end of the AVCN) and orthogonal to the lateral surface of the AVCN. In this slice plane, the anterior end was tilted $\sim 40^{\circ}$ dorsal to the horizontal plane. "Tuberculoventral tract" slices were cut orthogonal to the lateral surface of the AVCN and approximately parallel to the intranuclear fibers connecting the DCN and AVCN.

The location and orientation of brain slices varied from experiment to experiment. To compare data across experiments, we registered the location of each slice to a 3D MRI atlas of the mouse brain with a resolution of $21.5 \mu \mathrm{m}$ (Johnson et al., 2010) using images of the brain collected during the slicing procedure. The tissue block was viewed from the side through a low-magnification stereo microscope using a front surface mirror turned $45^{\circ}$, and located beside the tissue block. The orientation of the mounting gimbal was adjusted before and during slicing to optimize the plane of section. The brain was photographed through the microscope before and after each cut to record the anatomical location of the extracted section relative to the brainstem block (Fig. 1C, step 1).

In the MRI atlas, the cochlear nuclei were identified and labeled manually. Photographs of the brain taken during the slicing procedure were scaled and aligned with an image of the atlas to define the location of each slice (Fig. 1C, step 2). Next, a schematic image of the slice anatomy was generated by digitally slicing the atlas data (Fig. $1 C$, step 3 ), and the photos of the slice taken in the recording chamber were aligned with the schematic slice image (Fig. 1C, step 4). This process fully specifies the scaling and orientation of the slice within the 3D MRI atlas. Finally, the location of each cell was marked manually. A cochleotopic atlas (Muniak et al., 2013) was superimposed on the MRI atlas to determine the arrangement of the isofrequency sheets and tonotopic axis within the slice.

Electrophysiology. Following dissection, slices were incubated for at least $30 \mathrm{~min}$ at room temperature in artificial CSF (ACSF) containing the following (in mM): $122 \mathrm{NaCl}, 1.75 \mathrm{KCl}, 1.25 \mathrm{KH}_{2} \mathrm{PO}_{4}, 25 \mathrm{NaHCO}_{3}, 10$ glucose, 3 myo-inositol, 2 sodium pyruvate, 0.4 ascorbic acid, $3 \mathrm{CaCl}_{2}$, and $1 \mathrm{MgSO}_{4}$, and bubbled with $95 \% \mathrm{O}_{2}$ and $5 \% \mathrm{CO}_{2}$ to a $\mathrm{pH}$ of 7.4. Slices were then secured in a $300 \mu \mathrm{l}$ recording chamber and superfused with a $7 \mathrm{ml}$ recirculating supply of oxygenated ACSF containing $180 \mu \mathrm{M}$ MNI-caged-L-glutamate and $360 \mu \mathrm{M}(S)$ - $\alpha$-methyl-4-carboxyphenylglycine, a nonselective group I/II metabotropic glutamate receptor antagonist (Tocris Bioscience). The solution was pumped through the recording chamber at $\sim 2 \mathrm{ml} / \mathrm{min}$ using a peristaltic pump driven by a geared stepper motor to maintain a precisely controlled flow rate. A $10 \mathrm{ml}$ drip chamber was used to minimize fluid pulsing generated by the pump. Smooth fluid flow was essential to achieving consistent photostimulation because changes in the fluid level and meniscus curvature can dramatically alter the focus of the laser beam. The stepper motor was separated from the peristaltic pump by a long drive shaft and was powered by quadrature sine-wave outputs from an audio amplifier. This eliminated high-frequency electrical transients and ensured that electrical noise was not transmitted from the motor into the fluid lines. Before reaching the recording chamber, ACSF was heated to $25^{\circ} \mathrm{C}$ with an inline heater. This temperature was chosen because we found that it resulted in increased synaptic release probability. Cells were visualized with an upright Zeiss Axioskop FS 2 microscope equipped with a water-immersion objective lens $(40 \times$ or $63 \times)$ and CCD camera (Quantix 57 or QuantEM 512SC, Photometrics).

Patch pipettes were pulled from 1.2-mm-diameter borosilicate glass with a P2000 puller (Sutter Instruments), and had a resistance of $\sim 3$ to 10 $\mathrm{M} \Omega$ in the bath. For most recordings, a cesium-based electrode solution containing QX314 (Tocris Cookson) was used to minimize potassium and sodium conductances. This resulted in quieter recordings, improved voltage-clamp of dendrites, and allowed cells to be voltage-clamped near $0 \mathrm{mV}$ for over $30 \mathrm{~min}$. The electrode solution contained the following (in mM): $128 \mathrm{CsMeSO}_{3}, 5 \mathrm{CsCl}, 10$ sucrose, 5 EGTA, 10 HEPES, 4 MgATP, 10 creatine phosphate, 0.3 GTP Tris, 3 QX314, and was adjusted to $\mathrm{pH}$ 7.3 with $\mathrm{CsOH}$. Electrode solutions also contained Alexa Fluor 488 or 568 (Invitrogen) to allow morphological identification. Whole-cell recordings were made with a Multiclamp 700A amplifier (Molecular Devices). After recordings were complete for each cell, the patch pipette was carefully removed and the dendritic tree of the cell was imaged using a $63 \times$ objective with either standard epifluorescence illumination and a camera, or two-photon laser scanning microscopy.

AVCN neurons are commonly characterized by their response to brief current injections; however, the use of a $\mathrm{Cs}^{+}$-based electrode solution makes this analysis problematic. In a subset of experiments, electrodes were first filled with a small quantity of a standard K-gluconate-based internal solution, followed by a larger volume of $\mathrm{Cs}^{+}$solution. This allowed cells to be physiologically characterized immediately after rupturing the cell membrane, as it typically took $\sim 15 \mathrm{~min}$ for sufficient $\mathrm{Cs}^{+}$ to diffuse to the tip of the pipette. The K-gluconate solution contained the following (in $\mathrm{mm}$ ): $126 \mathrm{~K}$-gluconate, $2 \mathrm{NaCl}, 6 \mathrm{KCl}, 10$ sucrose, 10 HEPES, 0.2 EGTA, 4 Mg-ATP, 10 creatine phosphate, and 0.3 GTP Tris. The $\mathrm{pH}$ was adjusted to 7.2 with $\mathrm{KOH}$, and the final osmolarity was $\sim 295$ mOsm.

For voltage-clamp, cells were held at $-61 \mathrm{mV}$ when measuring excitatory synaptic responses or near $-11 \mathrm{mV}$ when measuring inhibitory synaptic responses. Cells were monitored for the duration of each experiment to ensure that series resistance and holding current were within acceptable limits. Cells with access resistance $>30 \mathrm{M} \Omega$ were excluded from quantitative analysis of postsynaptic current (PSC) amplitude and kinetics, and those with access resistance $>60 \mathrm{M} \Omega$ were excluded entirely. Typically, the current required to hold cells at the target voltage was $<50 \mathrm{pA}$ at $-61 \mathrm{mV}$ or $200 \mathrm{pA}$ near $-11 \mathrm{mV}$. All reported voltages include a calculated $-11 \mathrm{mV} \mathrm{Cs}^{+}$-electrode solution junction potential.

Photostimulation. To measure connectivity and characterize synaptic responses, we used caged MNI-glutamate photostimulation to evoke action potentials in cells presynaptic to the patched cell while recording postsynaptic responses (Katz and Dalva, 1994). Photostimulation was performed with a $100 \mathrm{~mW}, 355 \mathrm{~nm}$ UV laser (Series 3500, DPSS Lasers) steered through the epifluorescence port of the microscope. The beam position was controlled with a pair of galvanometer-based scanning mirrors $(6510 \mathrm{H}$, Cambridge Technologies) combined with $100 \mathrm{~mm}$ scan and tube lenses (Thorlabs) embedded within the microscope. Laser power was monitored with a photodiode in later experiments. UV light pulses were controlled via the Q-switch of the laser combined with a fast shutter (Uniblitz, Vincent Associates). The laser spot was focused onto the sample with a $5 \times$ objective ( 0.95 numerical aperture Achroplan, Zeiss). The spot size was set to $\sim 90 \mu \mathrm{m}$ in diameter (measured at $1 / e$ of the maximum intensity) by adjusting the beam divergence with two $100 \mathrm{~mm}$ lenses mounted in front of the laser aperture. As the spot size was adjusted, its diameter was monitored and reported by software (www.acq4. org) that continuously fit a video image of the spot with a 2D Gaussian profile. The spot power at the sample plane was $\sim 20 \mathrm{~mW}$, as measured 
with a Newport 1917-R laser power meter and 818P-015-17W thermopile sensor.

Photostimulation pulses, physiological recordings, and galvanometer mirror commands were synchronized using a multifunction data acquisition device (PCI-6259, National Instruments) controlled by custom software (www.acq4.org) written in Python. The galvanometer mirror voltage commands were determined by calibrating the resulting laser spot position against the CCD camera frames. Scanning maps were designed by visually specifying the desired spot locations relative to the image of the slice on the computer monitor. To determine the optimal laser pulse duration, we photostimulated cells with a range of pulse durations while extracellularly recording their firing response. A pulse duration of $\sim 1$ ms was chosen to deliver $20 \mu \mathrm{J}$, which evoked at least one spike in most cells.

Cell characterization and mapping procedure. One of the primary goals of this study was to examine the relationship between patterns of synaptic connectivity and various properties of the postsynaptic cells. Thus, each cell was characterized through measurements in several different experimental protocols. Patched cells were directly photostimulated in cellattached mode before rupturing the cell membrane. The latency and number of action potentials elicited was used both to characterize the cell as well as to determine optimal stimulation parameters to ensure that the majority of cells would respond with at least one action potential. Five cells underwent more extensive profiling to determine the relationships among pulse energy, spot location relative to the soma, and the response of the cell. After rupturing the cell membrane, the current-voltage ( $I-V)$ relationship of the cell was measured with standard current injection and voltage step protocols.

We mapped the locations of synaptic inputs to the cell by photostimulating sites in a hexagonal grid, typically consisting of 100-300 points, over the visible surfaces of the cochlear nuclei. Each site was stimulated while holding the patched cell at either $-61 \mathrm{mV}$ to record EPSCs, or between -21 and $-1 \mathrm{mV}$ to record IPSCs. Photostimulation flashes of $10-40 \mu \mathrm{J}$ were generated by pulsing the laser Q-switch for $0.5-2 \mathrm{~ms}$. In experiments where the laser power was monitored, the flash duration was automatically adjusted to control the total energy delivered. For each stimulation, we recorded the membrane current for at least $300 \mathrm{~ms}$ before and after the laser flash. Stimuli were typically separated by $\sim 1.5 \mathrm{~s}$. Sites were stimulated in an order optimized to maximize the distance between subsequent stimulations, and adjacent sites were never stimulated within $10 \mathrm{~s}$ of one another. To reduce false positives, each site was usually stimulated three times per holding potential (for a total of six stimulations); however, this number was occasionally varied depending on the rate of spontaneous postsynaptic events of the cell. The response to each stimulation was recorded, along with the location of the stimulation site and an image of the laser spot to allow later verification of the scanning mirror calibration. These positions were automatically mapped to the 3D MRI atlas coordinate system, and subsequently to the tonotopic atlas to estimate the likely frequency location of each patched cell or stimulation site. The width of the laser spot $(90 \mu \mathrm{m})$ spans $\sim 0.3$ octaves within the tonotopic atlas.

Analysis. The currents recorded during photostimulation represent three classes of events: spontaneous synaptic currents, evoked synaptic currents, and currents produced by direct photostimulation of the recorded cell. One of the major challenges of photostimulation mapping is to separate these components and analyze them independently. Ordinarily, polysynaptic activation presents a fourth class of events that must be minimized and discriminated. However, local excitatory inputs were rarely encountered in these experiments, and thus polysynaptic activation is unlikely. Our approach to separating spontaneous, evoked, and direct currents is summarized in Figure 2. Whole-cell recordings are first filtered to remove $60 \mathrm{~Hz}$ line noise and high-frequency noise sources. Next, we search for large inward currents beginning $<4 \mathrm{~ms}$ following the stimulus onset. Such currents are often the result of direct glutamate stimulation of the postsynaptic cell. If present, this current was fit against a shape composed of the product of an exponential rise and the sum of two exponential decays, as follows:

$$
y(x)=\left(1-e^{-t / \tau_{r}}\right)^{p}\left(A e^{-t / \tau_{d 1}}+B e^{-t / \tau_{d 2}}\right) .
$$

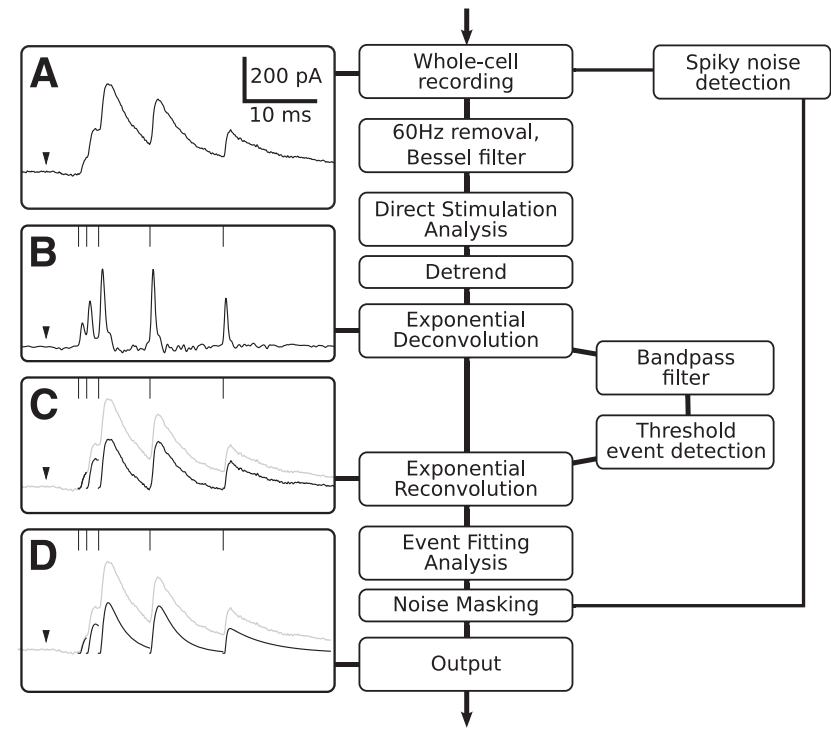

Figure 2. Event detection algorithm. The algorithm is described more thoroughly in Materials and Methods. $A$, Whole-cell recording data are filtered to remove noise and detrended. In some cases, currents due to direct stimulation are subtracted from the traces. $\boldsymbol{B}$, Next, the trace is exponentially deconvolved to emphasize the rising phase of each synaptic event. The deconvolved trace is used to determine the starting time of each event. C, Segments of the deconvolved signal are reconvolved to yield an estimated shape for each event as if it were isolated from prior events. $\boldsymbol{D}$, The reconvolved event traces are fit to a function (Eq. 2) to measure the onset time, amplitude, and time constants.

Traces were fit using the Levenberg-Marquardt algorithm in SciPy (http://www.scipy.org; see scipy.optimize.leastsq), combined with a simple parameter-space search to reduce the probability of improper fitting. The results of this fitting procedure were saved for further analysis. In some cases, the fit depolarization shape was subtracted from the recording to improve our ability to measure synaptic events that occurred during the falling phase of the direct response.

Recordings were then detrended and exponentially deconvolved (Richardson and Silberberg, 2008) to help separate overlapping events and emphasize the fast rising phase of synaptic currents. The deconvolved signal was used to determine the onset time of each synaptic event and then partitioned into a single trace segment per event. The segmented events were then exponentially reconvolved to give an estimate of the shape of the event in the absence of any preceding events. Finally, the reconvolved events were fit to a synaptic conductance-like function that is the product of rising and falling exponentials, as follows:

$$
y(x)=A\left(1-e^{-x / \tau_{r}}\right)^{2} e^{-x / \tau_{d}} .
$$

For events that occurred in rapid succession, this method provided a good estimate of the onset time and amplitude of each event, but distorted their rise/decay kinetics. For well isolated events, the exponential deconvolution and reconvolution had little effect and thus the rise/decay kinetics of the event could be accurately measured.

The presence of spontaneous events and the probabilistic nature of synaptic transmission led to errors in the analysis of input sites in photostimulation mapping experiments. Typical rates of spontaneous IPSCs were $0.1-2 \mathrm{~Hz}$ for bushy cells and $0.5-6 \mathrm{~Hz}$ for stellate cells, while spontaneous EPSCs occurred at $10-20 \mathrm{~Hz}$ for both cell types. To reduce the probability of detecting false positives, most sites were stimulated three times. For cells with a high rate of spontaneous events, additional rounds of stimulation were necessary to improve the identification of evoked events. In cases where the spontaneous rate was low, two stimuli were sufficient. We also used high-Ca ${ }^{2+}$ ACSF to increase synaptic release probability and thus reduce the rate of false negatives.

Most photostimulation mapping studies identify evoked events by comparing the total charge transfer during equal periods before and after stimulation (Shepherd et al., 2003; Jin et al., 2006; Barbour and Callaway, 
2008). We found this method to be sensitive to noise and insensitive to photostimulation responses that evoke little charge transfer relative to spontaneous activity. In addition, charge transfer from synaptic events was obscured by direct stimulation currents for inputs close to the postsynaptic cell. To address these problems, we developed a statistical metric based on the onset times of detected events to distinguish spontaneous from evoked events. The method assumes that the times of occurrence of spontaneous PSCs follow the statistics of a Poisson process, and computes the probability that this process generates a particular series of events. This method is similar to one proposed by Chase and Young (2007) for measuring first spike latencies of neurons in response to sensory stimuli and in the presence of spontaneous activity.

The statistic was computed in three steps. First, we determined the mean rate of spontaneous events by counting the number of events in the prestimulus region of each recording (this region did, on rare occasions, contain events evoked by the preceding stimulation as well). For cells with a low spontaneous event rate $(<0.3 \mathrm{~Hz})$, the mean rate was determined by averaging over all recordings for the cell. For cells with higher or erratic spontaneous rates, we measured the rate for each stimulus and applied a Gaussian smoothing filter $(\sigma \approx 30 \mathrm{~s})$ over time to generate a per-recording estimate of spontaneous rate.

Second, for each stimulation site we combined the times of poststimulus events across all stimulus repetitions into a single pool. The spontaneous rates measured during the prestimulus period were also summed. We then computed a metric that indicated whether the pooled event times were likely to have been generated by a Poisson process with the summed spontaneous rate. To compute the metric, let the function $N(t)$ be the number of events occurring at time $\leq t$, relative to the stimulation onset. Then, for any time $t$ after stimulus, we can compute the probability that a Poisson process would generate $N(t)$ events in a time window of width $t$ using the survival function for a Poisson distribution with spontaneous rate $s$, as follows:

$$
\operatorname{PoisSF}(t)=1-e^{-s t} \sum_{i=0}^{N(t)-1} \frac{(s t)^{i}}{i !}
$$

Third, we computed the probability that the response in the evoked window was not due to spontaneous activity by taking the minimum of the survival function between $t=t_{\min }(2 \mathrm{~ms})$ to $t=t_{\max }(200 \mathrm{~ms})$. Because taking the minimum involves multiple comparisons, a correction was needed to compute a probability from this metric. The correction was determined by measuring the scores for many repeated trials of a simulated Poisson process over a range of values for $s t_{\max }$ and computing a table of $p$ values.

This metric has an important advantage over simply computing the survival function at a specific time point in that it is sensitive to the timing of events as well as their rate. Events that cluster immediately after the stimulation time will yield a higher score. Thus, the metric can help identify evoked events even in the presence of high spontaneous rates of activity, as long as the presynaptic cell responds quickly and with reliable latency after the stimulation. At the same time, the metric can detect synaptic inputs that have longer latency or poor precision, but nevertheless increase the mean event rate over a longer time period.

For each map, the set of sites with evoked responses was determined by selecting those sites whose metric was less than some threshold (usually 0.001-0.01). The threshold was determined for each map based on the rate of spontaneous events and the strength of evoked events. In a small number of cases, unstable membrane currents or sudden changes in the spontaneous event rate that were clearly not associated with the stimulus resulted in the incorrect detection of input sites; these were manually removed from the results.

Classification of cell types. Classification of cell type was difficult in these experiments because we primarily used a cesium-based electrode solution and thus could not rely on current-clamp data. Cell identification was further complicated by incomplete dye labeling and, in some cases, by ambiguous morphology. To classify as many cells as possible, we used several complementary criteria. Cells were classified as bushy (55 cells), stellate ( 24 cells), or ambiguous/unusual (10 cells) on the basis of morphology, spontaneous PSC kinetics, and, when available, $I-V$ curves. Morphological classification was made by ranking the cells on a scale from 1 to 5 (1, bushy; 3 , ambiguous; 5 , stellate) and averaging results from three independent experienced observers. Average values $\leq 2$ were considered bushy; values $\geq 4$ were considered stellate. Additionally, spontaneous PSC kinetics could be used in most cells to distinguish between categories by measuring the ratio between the decay time constant of excitatory and inhibitory PSCs (Xie and Manis, 2013). Cells with a ratio of $>0.5$ were considered stellate, whereas cells with a ratio of $<0.2$ were considered bushy. In a subset of cells, $I-V$ curves were measured while recording with a potassium gluconate electrode solution. These cells could be classified by their responses to short current injection pulses (Wu and Oertel, 1984). For cells patched with cesium electrode solution, a similar (but less reliable) classification could be made based on the response of the cell to direct stimulation while recording in cellattached mode. Cells for which direct stimulation elicited a train of action potentials were almost always stellate cells, whereas cells that responded with a single action potential could be either type.

Cells expressing exclusively bushy-like or stellate-like characteristics were classified accordingly. Although it is clear that bushy and stellate cells represent two distinct populations, many of the differences between these populations are expressed on a continuum (Webster and Trune, 1982; Rothman and Manis, 2003a; Typlt et al., 2012); some cells express properties that appear to be intermediate between the two populations, while other cells have characteristics of both populations. Despite this difficulty, it is still beneficial to classify cells based on the canonical bushy and stellate categories. In addition, cells having insufficient data to make a clear judgment were classified as "ambiguous," and those expressing characteristics of both cell types were classified as "unusual."

Stellate cells were further classified as either T-stellate or D-stellate based on morphology and membrane properties. T-stellate cells typically have dendrites constrained to a narrow isofrequency region, whereas D-stellate cells have dendrites that cross frequency planes (Oertel et al., 1990; Doucet and Ryugo, 2006). Cell reconstructions were overlaid onto the maps of isofrequency contours generated using the cochleotopic atlas from Muniak et al. (2013), and cells whose dendrites were oriented orthogonal to the isofrequency contours were flagged as candidate D-stellate cells. We often had poor confidence in this morphological characterization because of incomplete fills, and thus combined it with an analysis of hyperpolarization-activated cation current $\left(I_{\mathrm{h}}\right)$ kinetics (Fujino and Oertel, 2001), which could be measured in voltage-clamp with $\mathrm{Cs}^{+}$-containing electrodes. We measured the activation time constant of the $I_{\mathrm{h}}$ current in response to a voltage step from -61 to -141 $\mathrm{mV}$. Cells with time constants $<20 \mathrm{~ms}$ and D-stellate morphology were considered likely D-stellate cells (two cells). The remainder were simply labeled "stellate" and likely are primarily T-stellate cells (22 cells)

Statistical analysis. Many of the samples we compared for differences were not normally distributed, so significant differences were detected using a custom permutation resampling function. First, the difference between the means of two samples was computed. Next, values were randomly shuffled between the two samples while keeping the sample sizes constant, and the difference in the means of each permuted sample pair was computed. Finally, the $p$ value was determined as the fraction of times the absolute value of the permuted mean difference exceeded the originally measured difference. For each comparison, we performed 10,000 permutations. Where this function determined a $p$ value of 0 , we have reported $p<10^{-4}$. The SciPy library for Python (http://www.scipy.org) was used to compute single-sample $t$ tests (scipy.stats.ttest_1samp) and Pearson correlation coefficient (scipy.stats.pearsonr). Multiple groups were compared by ANOVA using R (http://www.r-project.org) and appropriate post-tests. Data are presented as the mean $\pm \mathrm{SD}$.

\section{Results}

\section{Cell classification and localization}

The cells in this study were located almost entirely within the AVCN; a few cells were located in the posteroventral cochlear nucleus (PVCN) or near the dorsal margin of the AVCN (see Fig. $3 A, B)$. Most cells were located within the central AVCN, whereas 
A
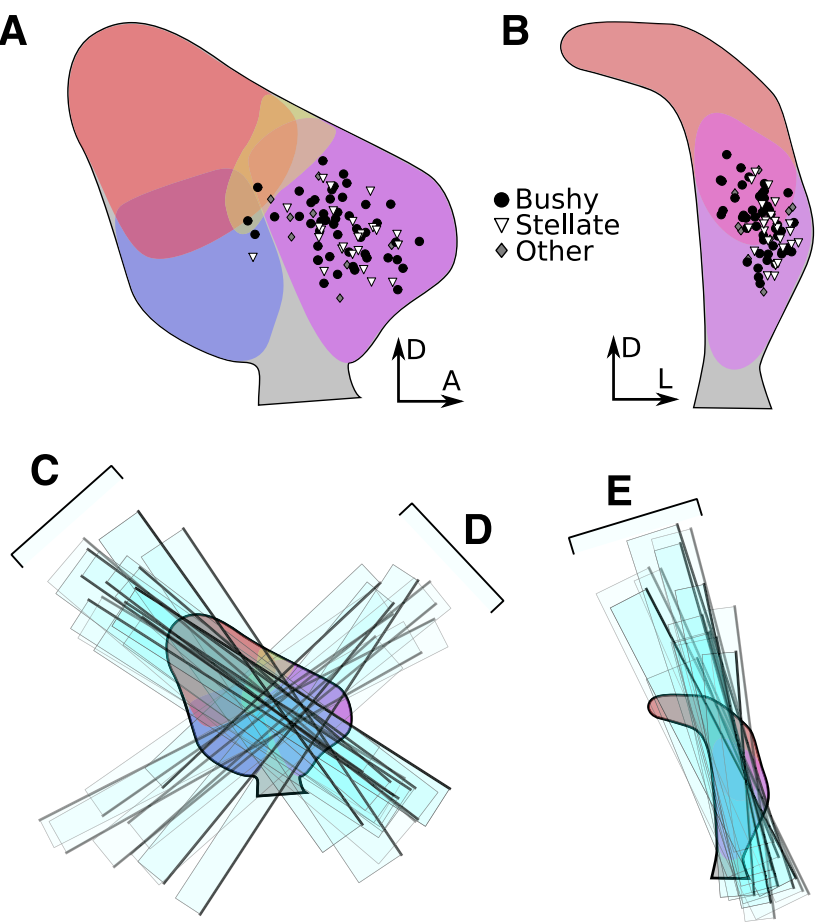

Figure 3. Locations of data sampled in this study. $\boldsymbol{A}$, Sagittal view of the cochlear nucleus atlas with locations of patched cells indicated (circle, bushy; triangle, stellate; diamond, other). $\boldsymbol{B}$, Coronal view of the atlas with the same cell locations marked. $\boldsymbol{C}$, Rectangles indicate the locations of a selection (approximately one third) of tuberculoventral tract slices aligned against the atlas in sagittal view. Dark edges indicate the side of the slice that was visible during the experiment. D, Locations of ascending branch slices aligned against the atlas in sagittal view. $\boldsymbol{E}$, Locations of parasagittal slices aligned against the atlas in coronal view. A, Anterior; D, dorsal; L, lateral.

the ventral and rostral borders were excluded entirely. Stellate cells were confined to the lateral portion of the nucleus. In contrast, bushy cells were found throughout the sampled area, including the medial extent of the nucleus. Slices were taken in three different orientations, indicated in Figure $3 C-E$. This study did not include any granule cells.

Fifty-five of 89 cells were classified as bushy, and 24 of 89 cells were classified as stellate based on both morphology and PSC kinetics, as described in Materials and Methods. Bushy cells had spontaneous IPSCs with a decay time constant much longer than their spontaneous EPSC decay time constant (IPSC, $\tau=14 \pm 6.8$ ms; EPSC, $\tau=0.50 \pm 0.11 \mathrm{~ms}$ ), whereas stellate cells had nearly equal spontaneous EPSC and IPSC decay time constants (IPSC, $\tau=3.6 \pm 0.86 \mathrm{~ms}$; EPSC, $\tau=2.6 \pm 0.92 \mathrm{~ms}$; Fig. $4 A, B)$. These definitions are in agreement with those of Xie and Manis (2013), although the time constants in the present study are longer because recordings were performed at a lower temperature (25 vs $34^{\circ} \mathrm{C}$ ). Five cells were classified as ambiguous because they lacked unambiguous morphological or PSC data. Another 5 of 89 cells were classified as unusual because they appeared to have morphological and physiological characteristics of both bushy and stellate cells. Cells classified as ambiguous or unusual are excluded from this report, except where indicated.

All of the cells included in this study had fast spontaneous EPSCs typical of those associated with spontaneous release at auditory nerve terminals. However, 10 cells also had a population of slower spontaneous EPSCs. These were detected in seven bushy cells, with decay time constants between 1.5 and 3 ms (Fig. $4 C$ ). Three stellate cells had a subset of spontaneous EPSCs with a decay time constant clearly different from those of their auditory nerve spontaneous EPSCs (2.5, 11, and $25 \mathrm{~ms}$; Fig. $4 D)$. Bimodal EPSC distributions have not been reported previously in VCN neurons and were only apparent in this study due to the long recording times required to carry out photostimulation mapping.

In addition to the PSC decay time constants, we measured the amplitude and rate of spontaneous events. The rate of spontaneous IPSCs was significantly lower in bushy cells than in stellate cells (bushy, $0.46 \pm 0.59 \mathrm{~Hz}$; stellate, $3.1 \pm 2.9 \mathrm{~Hz}$; permutation, $\left.p<10^{-4}\right)$, whereas the rate of spontaneous EPSCs was not different (bushy, $13 \pm 8.2 \mathrm{~Hz}$; stellate, $12 \pm 7.1 \mathrm{~Hz}$; permutation, $p=0.73)$. Conversely, the amplitude of spontaneous IPSCs was not different between cell types (bushy, $20 \pm 12 \mathrm{pA}$; stellate, $24 \pm$ $11 \mathrm{pA}$; permutation, $p=0.37)$, whereas the amplitude of spontaneous EPSCs was larger in bushy cells than in stellate cells (bushy, $-35 \pm 9.8 \mathrm{pA}$; stellate, $-19 \pm 6.3 \mathrm{pA}$; permutation, $p<$ $\left.10^{-4}\right)$. These results confirm that synaptic inputs differ between bushy and stellate cells, and thus the functional roles of these inputs may differ across cell types as well.

\section{Responses to direct stimulation}

Glutamate uncaging does not excite all cells equivalently. The firing pattern of a photostimulated cell depends on the intrinsic excitability of the cell, the laser power, the position of the laser spot relative to the cell, and the depth of the cell within the slice. To measure the relationship between the photostimulation parameters and typical cellular responses, we photostimulated 59 cells at least once while recording in the cell-attached configuration. The sample was limited because cells that are deeper or in different regions of the slice were excluded from this analysis, even though they may have contributed to evoked responses during mapping experiments.

The direct responses of AVCN cells varied depending on the cell type. Stellate cells most frequently (12 of 18 cells) responded with a train of spikes, which could last for tens or hundreds of milliseconds (Fig. 5A). In contrast, most bushy cells (31 of 33 cells) responded with a single spike when photostimulated, regardless of the pulse duration (Fig. $5 B$ ). These spiking patterns are consistent with the intrinsic responses to current injection for bushy and stellate cells (Oertel, 1983), and likely result from the sustained activity of glutamate in the slice following photostimulation. Due to the relative scarcity of local excitatory inputs found in this study, the evoked spike trains are unlikely to result from polysynaptic activation.

The relationship between the number of evoked spikes and the distance from the laser spot to the soma was measured by repeated photostimulation at densely spaced $(\sim 30 \mu \mathrm{m})$ locations in five cells (Fig. 5C). These measurements showed that the spatial resolution for photostimulating single neurons was not consistent-whereas some cells respond only to direct activation over the soma, others respond to stimulation over their dendrites or over regions of the slice separated from the cell. For four of five cells, the maximum distance that evoked spikes (measured from the cell body to the center of the laser spot) was $<100$ $\mu \mathrm{m}$. One cell responded to photostimulation up to $150 \mu \mathrm{m}$ away and was selected for this analysis specifically because of its high excitability.

After photostimulation responses were recorded in the cellattached mode, the amplitude and kinetics of direct photostimulation responses were evaluated in whole-cell recordings. In most cases, direct stimulation resulted in currents of several hundred picoamperes lasting for tens of milliseconds (Fig. 5D, trace c). 
The duration of these direct stimulation currents far outlasts the $\sim 1 \mathrm{~ms}$ laser flash, indicating the sustained activity of glutamate in the slice following photostimulation. In 31 of the 85 cells tested, the evoked current had a second component that persisted for hundreds of milliseconds. These slow evoked currents do not appear to be synaptically mediated, and likely contribute to the sustained spiking evoked by photostimulation. The amplitude of this slow component varied widely depending on the exact location of the laser flash over the cell (Fig. 5D), which may indicate that glutamate receptors or receptor subtypes are not uniformly distributed on AVCN cells.

For each cell, we photostimulated sites in a grid with $90 \mu \mathrm{m}$ spacing, then counted the number of sites with direct responses $>20 \mathrm{pA}$. Figure $5 E$ shows these counts separated by cell type. We found that stellate cells typically had direct stimulation currents in about twice as many sites as bushy cells, which likely reflects differences in dendritic morphology and intrinsic excitability between stellate and bushy cells.

\section{Spatial organization of input sites}

Photostimulation maps of both excitatory and inhibitory synaptic currents were analyzed to determine the locations of presynaptic cells in the map. Both bushy and stellate cells received inhibitory input from regions in both the VCN and DCN, and occasionally from the dorsal border of the AVCN. Excitatory inputs were rare and tended to arise from locations close to the recorded cell. In the following sections, we discuss each source region separately.

\section{Inhibitory input from the VCN}

Eighty-nine percent of cells (59 of 66 cells) had detectable evoked inhibitory inputs that arose from within the VCN, usually appearing as a contiguous cluster of sites surrounding the postsynaptic soma (Fig. 6). The majority of these inputs were evoked from sites in the AVCN or occasionally the PVCN and are presumed to arise from D-stellate cells, which are the only known inhibitory neurons in the VCN. The area over which evoked inputs were detected was highly variable in size and shape, particularly with respect to the alignment of isofrequency sheets. Although the inputs to some cells were aligned with the isofrequency sheets (Fig. 6A,E) or across the isofrequency sheets (Fig. $6 D$ ), in most cases the organization of inputs had no apparent relationship to the tonotopic axis. The two D-stellate cells in our dataset both had inhibitory input from nearby in the AVCN, indicating that these cells may form a recurrent inhibitory network.

Stellate and bushy cells process and emphasize different aspects of their auditory input. On this basis, we predicted that the spatial organization of their inhibitory inputs would differ as well. Stellate cells typically had three times as many VCN stimulation sites that generated detectable inhibitory input than bushy cells (Fig. 7A; bushy, $7.7 \pm 5.4$ sites; stellate, $21 \pm 13$ sites; permutation, $\left.p<10^{-4}\right)$. Because this difference was so large, we next investigated which aspects of the input maps differed between cell types. T-stellate cells, which make up approximately half of the cells in the VCN, have dendritic arbors that extend in a planar configuration within isofrequency planes. In contrast, bushy cells have compact, dense dendritic arbors that do not extend appreciably in any direction (Fig. 1A). We predicted that the spatial organization of inhibitory inputs would reflect the dendritic morphology of each cell type. Thus, T-stellate cells would receive input from VCN sites that extended a greater distance along the isofrequency sheets than the inputs to bushy cells, whereas the spread of input sites along the orthogonal axis would be similar between the two cell types.

To test this idea, we measured the SD of the locations of inputs to each cell along the axis that is parallel to isofrequency sheets and the lateral surface of the nucleus (Fig. $7 B$ ). Using this measure, we found no difference between bushy and stellate cells in the spatial spread of inputs (bushy, $149 \pm 54 \mu \mathrm{m}$; stellate, $176 \pm$ $69 \mu \mathrm{m}$; permutation, $p=0.22$ ). Similarly, we found no significant difference between cell types in the width of the input area along the isofrequency axis orthogonal to the lateral surface of the nucleus (data not shown; bushy, $69 \pm 35 \mu \mathrm{m}$; stellate, $97 \pm 16$ $\mu \mathrm{m}$; permutation, $p=0.08$ ). These results were unexpected because it appears that the longer dendrites of T-stellate cells do not contribute significantly to the spatial spread of inhibitory inputs, suggesting that T-stellate cells may preferentially receive VCN inhibitory input to their proximal dendrites. This is consistent with anatomical evidence that synapses onto the distal dendrites of T-stellate cells are comparatively sparse (Smith and Rhode, 1989). Alternately, it may be the case that some inputs were not detected due to poor voltage-clamp at the distal dendrites.

Given the lack of any significant difference in the inhibitory input areas between bushy and stellate cells, it follows that the overall difference in input area should be apparent in the axis orthogonal to the isofrequency surfaces. Indeed, this was the case; the SD of input locations along this axis was larger in stellate cells than in bushy cells (bushy, $79 \pm 37 \mu \mathrm{m}$; stellate, $119 \pm 42 \mu \mathrm{m}$; permutation, $p=0.0036$ ). This result may have important functional implications because it suggests that the two cell types integrate inhibitory inputs from different frequency ranges. To verify this, we estimated the center frequency of each stimulus site $\left(\mathrm{CF}_{\text {site }}\right)$ using the cochleotopic atlas constructed by Muniak et al. 
A

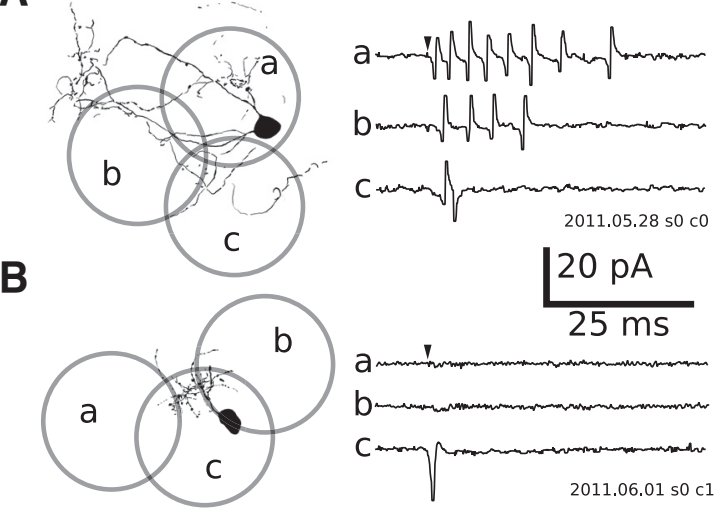

D

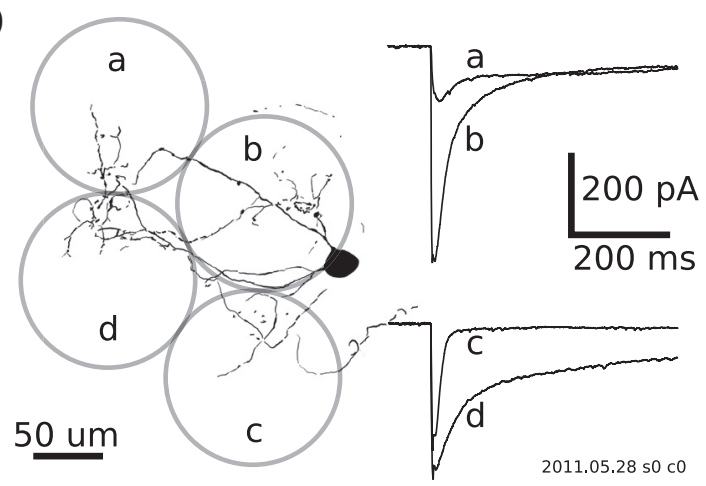

C

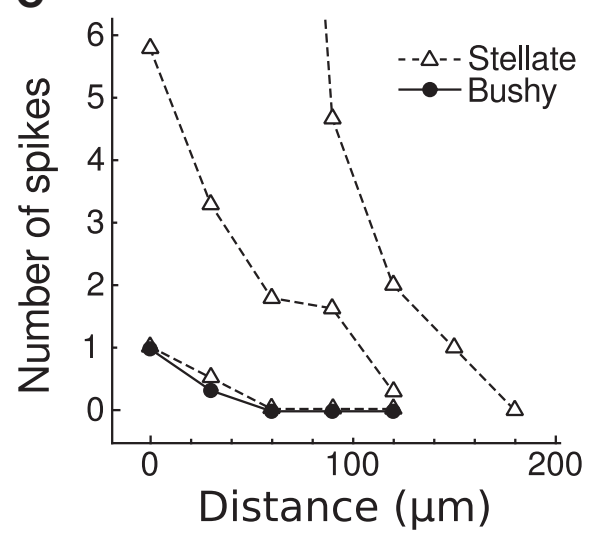

E

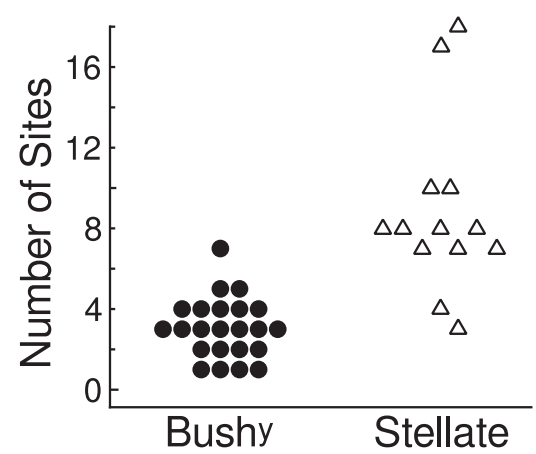

Figure 5. Typical responses to direct photostimulation. $\boldsymbol{A}$, Example cell-attached, voltage-clamp recordings (a-c) obtained with photostimulation at three locations (a-c) over a stellate cell. $\boldsymbol{B}$, Similar cell-attached recording on a bushy cell. C, Profiles of one bushy cell (circles) and three stellate cells (triangles) showing the number of spikes fired versus the distance from the cell soma to the center of the laser spot. $\boldsymbol{D}$, Example intracellular voltage-clamp recordings (a-d) obtained at four sites (a-d) over the same stellate cell. $\boldsymbol{E}$, Stellate cells have significantly larger direct response areas than bushy cells. Each point represents, for a single cell, the number of stimulation sites in a grid that produced a direct response peak larger than $-20 \mathrm{pA}$.

(2013). Next, we measured the SD of input site frequencies for each cell, scaled logarithmically such that the range is expressed in octaves, as follows: range $=\mathrm{SD}\left[\log _{2}\left(\mathrm{CF}_{\text {site }}\right)\right]$. A comparison of the input frequency range per cell is shown in Figure $7 C$. On average, bushy cells received inputs spanning \pm 0.3 octaves around the estimated frequency of the cell, whereas stellate cells received inputs spanning \pm 0.5 octaves. This difference was statistically significant (bushy, $0.31 \pm 0.15$ octaves; stellate, $0.49 \pm$ 0.18 octaves; permutation, $p=0.0035$ ). Figure $7 D$ summarizes the average input site distributions for bushy and stellate cells, after dividing the input site frequency by the target cell frequency. The average spatial distribution of the inputs further supports the conclusion that stellate cells receive AVCN inhibition from a wider frequency range than bushy cells.

\section{Inhibitory input from the DCN}

In contrast to the variable organization of inhibitory inputs from within the VCN, inhibitory inputs from the DCN were more predictably organized (Fig. 8). Previous studies have found that tuberculoventral cells in the DCN are the source of a tonotopically matched inhibitory input to AVCN cells (Wickesberg and Oertel, 1988, 1990; Saint Marie et al., 1991; Wickesberg et al., 1991; Ostapoff et al., 1999; Muniak and Ryugo, 2013). Our results are consistent with these studies. DCN inputs always originated from a narrow band oriented parallel to the isofrequency sheets in the DCN (Figs. 6B,E, $8 A, B$ ). In tuberculoventral slices, inputs always originated from sites in the deeper layers of the DCN, where tuberculoventral cells reside. Furthermore, the location of this band orthogonal to the isofrequency plane is well correlated with the location of the postsynaptic cell along the same axis (Fig. $8 C, D$; Pearson correlation coefficient $=0.87 ; p=2.5 \times 10^{-6}$; slope $=0.93$ ), consistent with a precise tonotopic projection.

We recorded maps from 42 cells from slices in which the tuberculoventral tract was expected to be intact and accessible by photostimulation. We excluded parasagittal slices for which the lateral surface of the DCN was not removed, tuberculoventral slices that were not well aligned with the tuberculoventral pathway, and all ascending branch slices. Of the maps from these slices, only $57 \%$ revealed DCN input to AVCN cells. It is unclear whether this reflects the normal distribution of DCN projections or is the result of interruption of the tuberculoventral tract fibers during slicing.

Next, we quantified the spatial organization of the DCN inputs (Fig. 9) for comparison to the AVCN inputs in Figure 7. Unlike the AVCN input pattern, we found no differences between bushy and stellate cells in the number of DCN input sites with evoked responses (Fig. 9A; bushy, $2.0 \pm 2.1$ sites; stellate, $2.5 \pm 3.0$ sites; permutation, $p=0.62$ ). The spatial range of DCN input sites within isofrequency sheets was also not different between bushy and stellate cells (Fig. 9B; bushy, $75 \pm 48 \mu \mathrm{m}$; stellate, $99 \pm 49 \mu \mathrm{m}$; permutation, $p=0.45)$. One $\mathrm{D}$-stellate cell was tested for DCN input and was found to have none.

We next compared the frequency range of inhibitory inputs between cell types and input regions (Fig. 9C). We found significant effects of both cell type (two-way ANOVA: $F_{(1,35)}=22.6$, $\left.p=3.3 \times 10^{-5}\right)$ and input region $\left(F_{(1,35)}=33.5, p=1.5 \times 10^{-6}\right)$, 
as well as a significant interaction between the two $\left(F_{(1,35)}=5.67, p=0.023\right)$. Post hoc comparisons using Tukey's HSD method demonstrated that the frequency span of DCN inputs was significantly narrower than the span of VCN inputs onto both bushy cells (DCN to bushy $=0.10 \pm 0.08$ octaves; $p=0.04)$ and stellate cells (DCN to stellate $\left.=0.16 \pm 0.09 ; p=1.5 \times 10^{-5}\right)$. Furthermore, the frequency span of $\mathrm{VCN}$ inputs was significantly wider in stellate cells than in bushy cells, as seen previously $(p=$ $\left.4.5 \times 10^{-5}\right)$, whereas the width of DCN inputs was not significantly different between bushy and stellate cells $(p=0.79)$. These results confirm that DCN cells provide tonotopically restricted inputs to AVCN cells, particularly compared with inhibitory inputs from the VCN.

\section{Inhibitory input from the dorsal border of AVCN}

Fifty-four maps were collected that included photostimulation sites over the granule cell area at the dorsal border of the AVCN (32 bushy cell maps, 17 stellate cell maps, 5 other). In 10 of these maps (2 bushy cell maps, 6 stellate cell maps, 2 other), a third distinct source of inhibitory input was revealed. In parasagittal slices, these inputs were found to lie along the dorsal edge of the AVCN, often appearing as small clusters of two to four stimulation sites that were usually spatially discontinuous with the larger region of AVCN inhibition close to the cell (Fig. 10A,D,E). In tuberculoventral slices, these inputs arose from sites along the dorsomedial border of the AVCN (Fig. $10 B, C)$. The strength and firing pattern of these dorsal-border inputs varied widely from cell to cell. Some cells showed long trains of fast evoked IPSCs (Fig. 10B), whereas others showed only a single slow evoked IPSC (Fig. 10A), similar to the responses evoked from DCN and central AVCN sites. Stellate cells were more likely than bushy cells to receive inhibitory input from the dorsal border of the AVCN (Fisher's exact test, $p=0.051$ ).

\section{Summary of inhibitory inputs}

To provide a full view of the spatial organization of local circuits in the AVCN, we plotted the inputs to all cells in a cell-centered map for each plane of section (Fig. 11). Some of the features previously discussed are immediately apparent: both cell types have similar patterns of spatial convergence, integrating inputs mainly from the DCN and nearby VCN with occasional input from the dorsal border of the AVCN. Inputs from VCN converge from a much broader area than those from the DCN, particularly along the axis orthogonal to the isofrequency lamina. Stellate cells integrate from a much larger area of the AVCN than bushy cells, although the DCN input areas to both
A Bushy

B

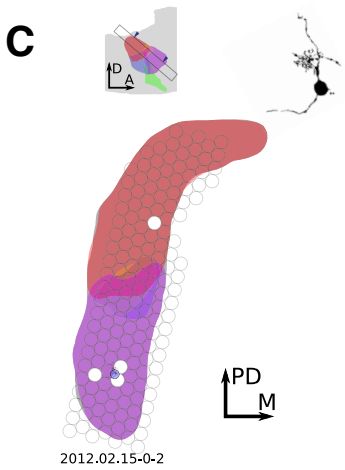

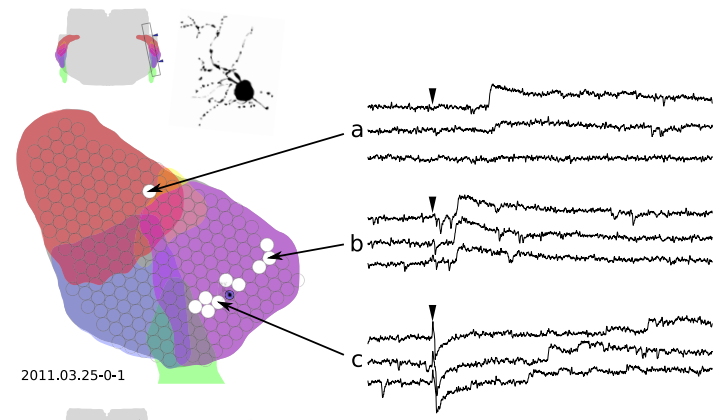

D Stellate
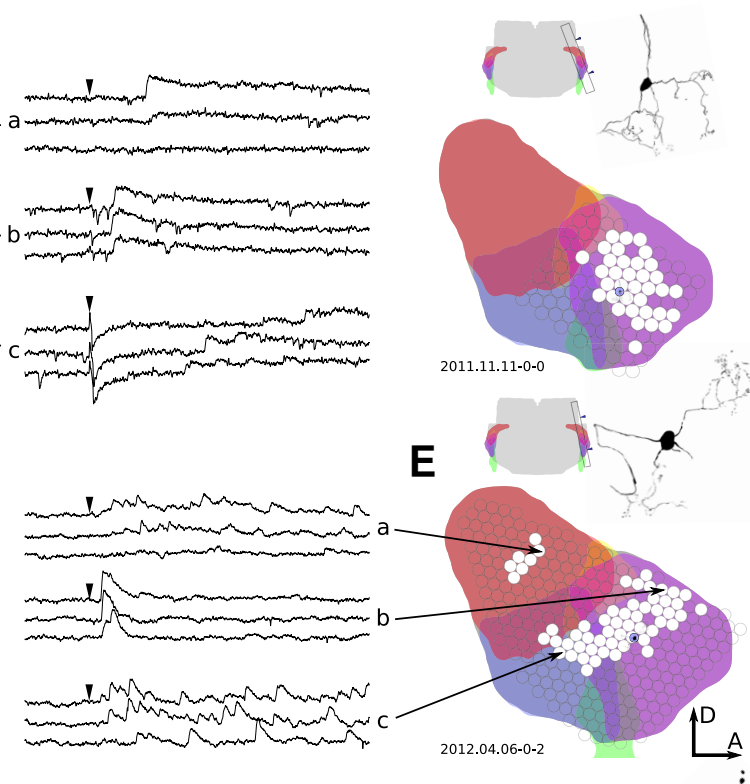
$\stackrel{A}{i}$

Figure 6. Example inhibitory connectivity maps for six AVCN cells. Each cell has input from the AVCN; four also have input from CN. $A, B$, Bushy cells in parasagittal slice plane. C, Bushy cell in tuberculoventral slice plane. D, E, Stellate cells in parasagitta slice plane. $\boldsymbol{F}$, Stellate cell in tuberculoventral slice plane. The example voltage-clamp recordings in this figure show a wide variety of response types, including weak $(\boldsymbol{A}, \boldsymbol{E})$, strong $(\boldsymbol{F})$, rapid firing $(\boldsymbol{E}, \mathrm{a}, \mathrm{c})$, single event $(\boldsymbol{A}, \mathrm{b}, \boldsymbol{F}, \mathrm{a}, \mathrm{b})$, late $(\boldsymbol{A}, \mathrm{c})$, unreliable $(\boldsymbol{A}, \mathrm{a}, \boldsymbol{F}$ slice from which that cell was patched. Arrowheads in the atlas schematic indicate the surface of the slice that was visible during the experiment. Colors are as follows: red, DCN; blue, PVCN; purple, AVCN; green, auditory nerve; yellow, granule cell area. Note that isions between anatomical regions may not be orthogonal to the plane of section; thus, the regions have some overlap in the schematic. When available, maps are accompanied by a morphological reconstruction of the cell based on two-photon microscopy or fluorescence images. The map of input locations is overlaid on a schematic of the slice, which was automatically generated by computing the appropriate section from a 3D atlas. Each circle indicates the location of multiple (typically three) laser stimulations; white filled circles indicate a presynaptic input was detected in the patch recording. The size of each circle indicates the illumination voltage-clamp recordings of evoked responses. Black arrowheads mark the time of photostimulation. A, Anterior; D, dorsal; L, lateral; $\mathrm{M}$, medial; $\mathrm{PD}$, posterodorsal. cell types are similar. Previously, Wickesberg and Oertel (1988) measured the patterns of connectivity to the AVCN by injecting horseradish peroxidase, which retrogradely labeled inputs from a narrow-frequency strip of the DCN as well as from a region of the VCN dorsal to the injection site. Although our results regarding DCN inputs to AVCN agree with theirs, we did not find any preference for local inputs within the AVCN to be located dorsal to the postsynaptic cell. In our sample, the AVCN input arises from regions that are largely centered on the target cell.

From the parasagittal slice maps in Figure $11 \mathrm{~A}$, it appeared that the VCN input regions for both bushy and stellate cells were 

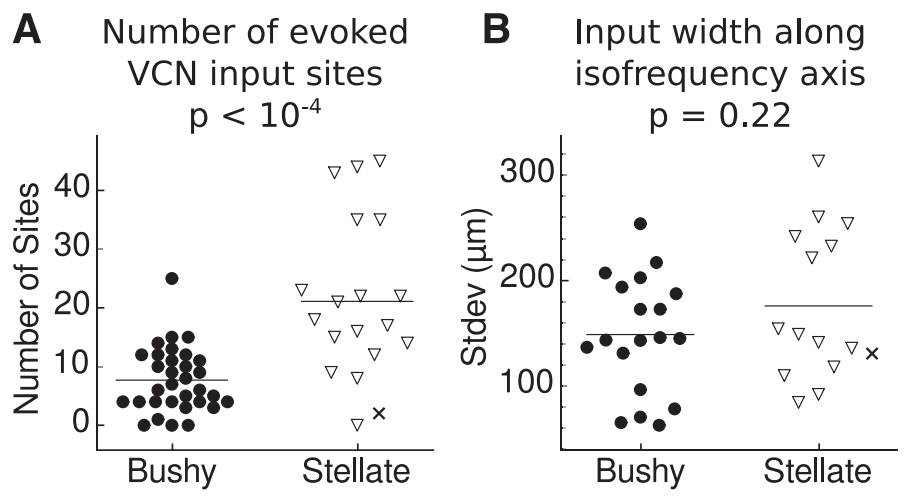

\section{Input width \\ across frequency \\ $p=0.003$}

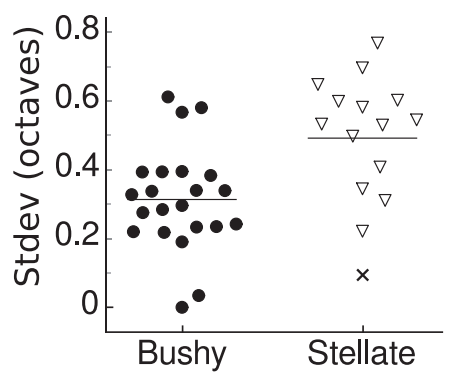

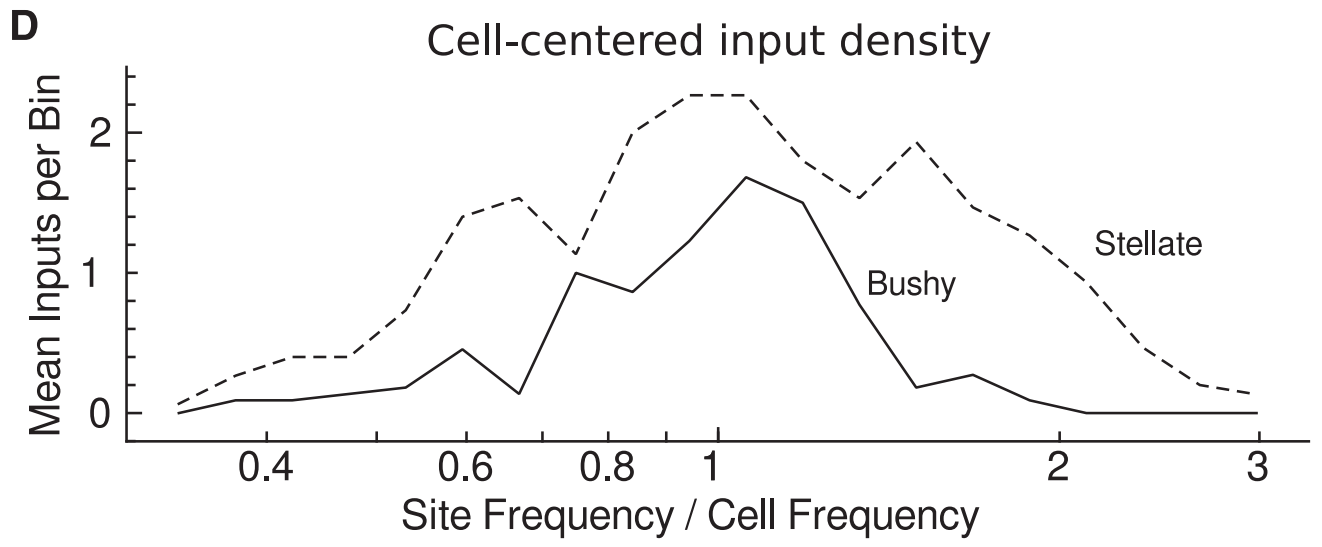

Figure 7. Bushy and stellate cells differ in their integration of AVCN inhibitory inputs. $A$, Stellate cells receive input from a larger number of stimulation sites than bushy cells. Each point in the scatter plot indicates the number of input sites detected for a single cell. $\boldsymbol{B}$, The difference in input area between bushy and stellate cells is not due to differences along the isofrequency axis (parallel to auditory nerve fibers). The plot shows the SD of the positions of input sites for each cell. $C$, Stellate cells integrate from a wider frequency range than bushy cells. The value of each point is computed as $S D\left[\log _{2}\left(C_{\text {site }}\right)\right]$ for the estimated frequencies of input sites to a cell. $\boldsymbol{D}$, Histograms showing the average density of input sites across frequency for bushy and stellate cells. All input sites were pooled and binned into equal frequency intervals. The plotted values indicate the average number of input sites per cell and bin. Stellate cells appear to receive more inhibition than bushy cells from both on-center and off-center frequencies.

wider along the $x$-axis (isofrequency axis from posteroventral to anterodorsal) than along the $y$-axis (tuberculoventral tract axis). To test this, we measured the per-cell SD of site locations across both axes for each cell type, then compared the $x$-axis and $y$-axis. For bushy cells, the spread is larger along the $x$-axis than the $y$-axis $(x$-axis $=151 \pm 50 \mu \mathrm{m} ; y$-axis $=94 \pm 38 \mu \mathrm{m}$; permutation, $p=0.006 ; n=12$ ). This result suggests that the terminal fields of D-stellate cells may preferentially extend along the isofrequency axis, and supports anatomical observations in a report by Arnott et al. (2004). For stellate cells, the same trend was apparent but was not statistically significant $(x$-axis $=176 \pm 70$ $\mu \mathrm{m} ; y$-axis $=146 \pm 48 \mu \mathrm{m}$; permutation, $p=0.25 ; n=12)$.

\section{Excitatory input from the AVCN}

Previous studies have raised the possibility of local excitatory connectivity in the VCN (Ferragamo et al., 1998a; Gómez-Nieto and Rubio, 2009; Oertel et al., 2011). To explore this possibility, we mapped the sources of evoked EPSCs in 75 cells by holding each cell at $-61 \mathrm{mV}$ during photostimulation. We detected excitatory inputs in only 5 of 75 cells ( 4 of 45 bushy cells, 1 of 22 stellate cells, and 0 of 8 other cells; Fig. 12). Local excitatory inputs were always found within $200 \mu \mathrm{m}$ of the postsynaptic cell body and did not appear to be restricted to a narrow isofrequency plane, suggesting that the postsynaptic cells may receive excitatory inputs from cells of different frequency (Fig. 12A), in contrast with their narrowly tuned auditory nerve inputs.
Three cells had large or discontinuous regions of excitatory input, indicating the presence of multiple presynaptic cells. This is surprising because if excitatory synapses were uniformly distributed across cells, then it would be unlikely to simultaneously find three cells with multiple inputs and 70 cells with no input. To quantify this, we used a resampling test to estimate the probability that, given eight synaptic inputs distributed uniformly across 75 cells, we would find at least 3 cells having at least two inputs each. Although we do not know the exact number of synaptic inputs in this dataset, eight is the minimum value supported by the mapping results and produces the most conservative probability estimate in the resampling test. The test confirmed that it is highly unlikely that uniformly distributed inputs would produce this pattern of inputs $(p=0.0008)$. Thus, the distribution of local excitatory inputs is nonuniform, suggesting that a small population of cells may be more predisposed to accepting local excitatory input.

Four cells had evoked excitatory inputs with slower decay kinetics than their spontaneous EPSCs. In three of the bushy cells with excitatory input, evoked EPSCs had a decay time constant of 2-3 ms, which is distinctly slower than the $\sim 0.5 \mathrm{~ms}$ decay of spontaneous auditory nerve EPSCs. Similarly, the stellate cell with excitatory input had evoked and spontaneous EPSCs with decay time constants of 30 and $1 \mathrm{~ms}$, respectively (Fig. 12D). Each of these cells also had a distinct population of spontaneous EPSCs with slower kinetics than auditory nerve spontaneous EPSCs (Figs. 3C, 12C). Four additional bushy cells and two additional 


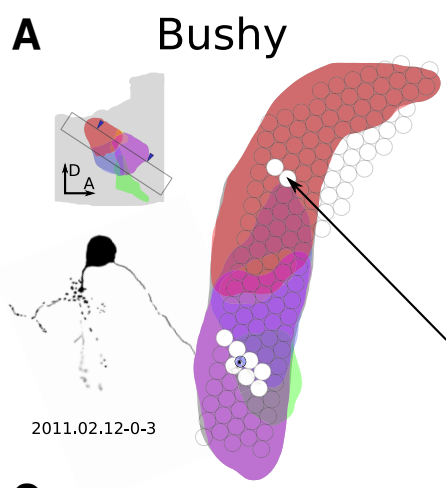

C

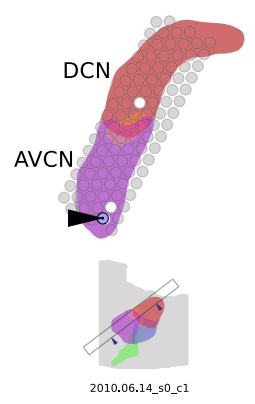

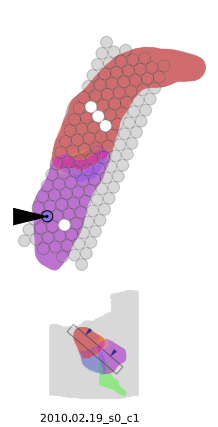
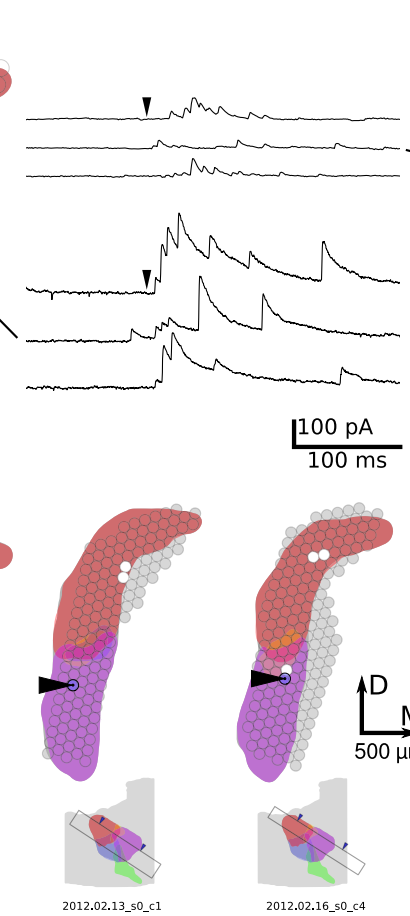

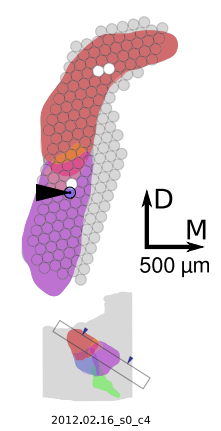

B Stellate

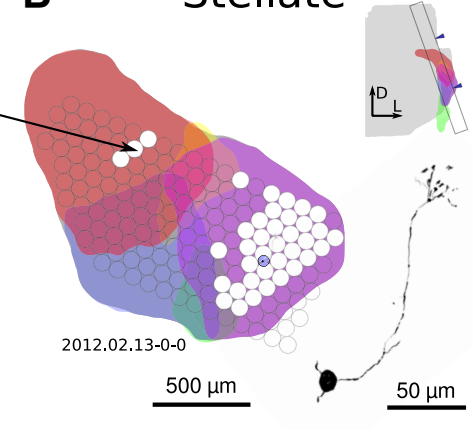

D

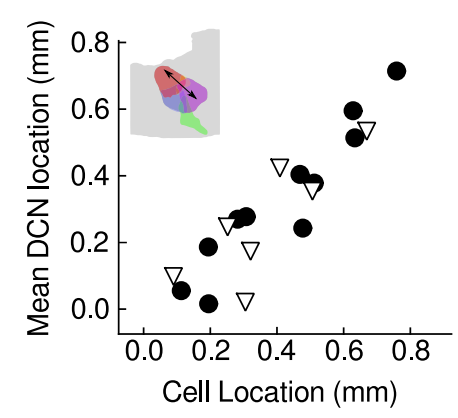

Figure 8. Inhibitory connectivity from DCN to AVCN. The format is described in Figure 6. A, Example map of bushy cell with DCN input. $\boldsymbol{B}$, Example map of stellate cell with DCN input. $C, D C N$ projections to VCN are focal and tonotopically organized. Maps from four representative cells in tuberculoventral slices show that the locations of DCN inputs are confined to a narrow region in the deep layer. Arrowheads indicate the location of the postsynaptic cell. $\boldsymbol{D}$, The position of inputs along the tuberculoventral tract axis (indicated in inset) correlates with the position of the postsynaptic cell along the same axis in the AVCN (circle, bushy cell; triangle, stellate cell). Position values are relative to an arbitrary origin within the 3D atlas. D, Dorsal; L, lateral; M, medial; A, anterior.

\section{A Number of evoked DCN input sites}

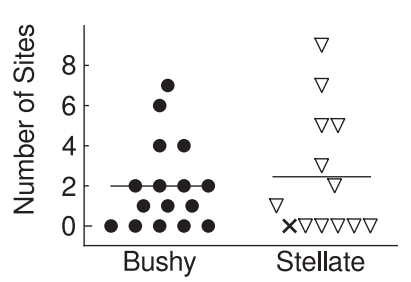

B Standard deviation of input location along Isofrequency axis
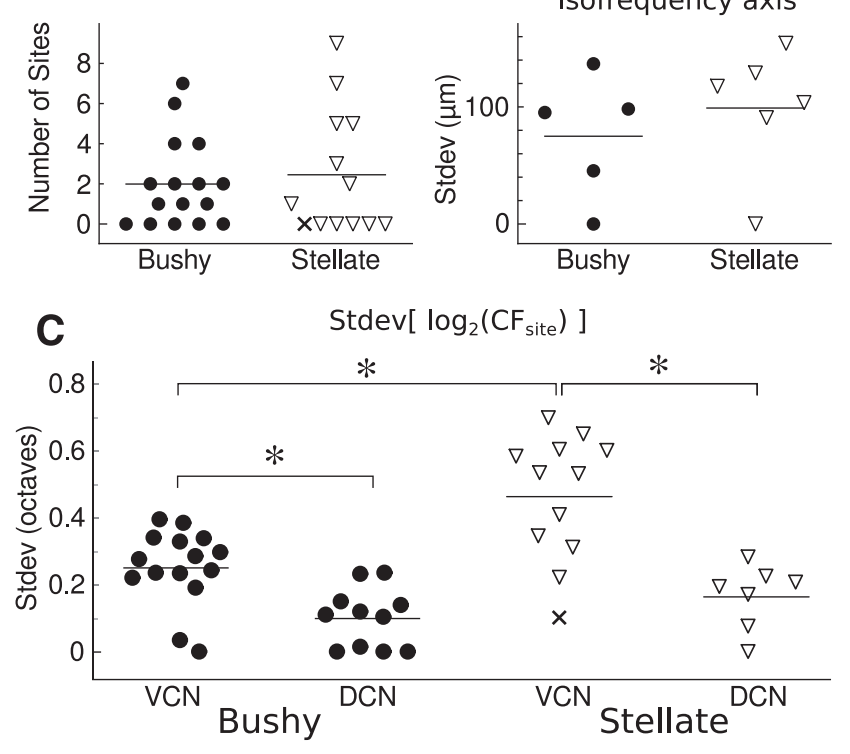

Figure 9. Bushy and stellate cells have similar integration of DCN inhibitory inputs. $\boldsymbol{A}$, Number of DCN stimulation sites with detectable input per cell. The bushy and stellate cell distributions are not significantly different. $\boldsymbol{B}$, Measurement of the width of DCN input area per cell. Each point in the plot indicates the SD of input locations along an axis approximately parallel to the DCN isofrequency sheets. Again, the bushy and stellate distributions are not significantly different. C, Comparison of the SD of input sites, in octaves, across cells. DCN inputs arise from a significantly narrower frequency span than AVCN inputs, for both bushy and stellate cells. circle, Bushy cell; triangle, stellate cell; $X$, D-stellate cell. ${ }^{*} p<0.05$, Tukey's HSD test. stellate cells exhibited similar slow spontaneous EPSCs, but had no detected evoked EPSCs. Given the overlap of cells having both spontaneous and evoked EPSCs with abnormally slow kinetics, it is likely that all seven bushy cells and three stellate cells having slow EPSCs were recipients of local excitatory input, although evoked EPSCs were only detected in five of these cells. Together, these findings indicate that local excitatory input within the VCN has slower kinetics than auditory nerve input. In addition, the firing patterns of excitatory interneurons are likely to differ from the firing patterns of auditory nerve fibers, suggesting different functional roles of these two excitatory sources.

\section{Differences in inhibitory synaptic inputs to VCN neurons}

The maps in Figures 7 and 11 show that stellate cells, on average, receive inhibitory inputs from a wider region of the VCN than do bushy cells. However, the spatial convergence of inputs is not the sole determinant of functional connectivity. In this section, we consider how the strength and kinetics of inhibition from the VCN and DCN varies with each of the target cell populations. Only cells with access resistance of $<30 \mathrm{M} \Omega$ were included in this analysis.

Xie and Manis (2013) reported previously that the decay time constant of IPSCs was faster in stellate cells than in bushy cells. To determine whether there are also differences between DCN and VCN inputs, we selected well isolated evoked events and compared their decay time constants for each input region and postsynaptic cell type. Our results are consistent with those previously reported. The decay time constants for VCN inhibition to bushy cells was $10 \pm 4.2 \mathrm{~ms}(n=10)$, and for DCN inputs to bushy cells was $19 \pm 4.7 \mathrm{~ms}(n=3)$. Although there appears to be a difference between these input regions, it became insignificant after correcting for the average spontaneous IPSC decay time constant for each cell. For stellate cells, VCN inhibition decayed with a 
A Bushy

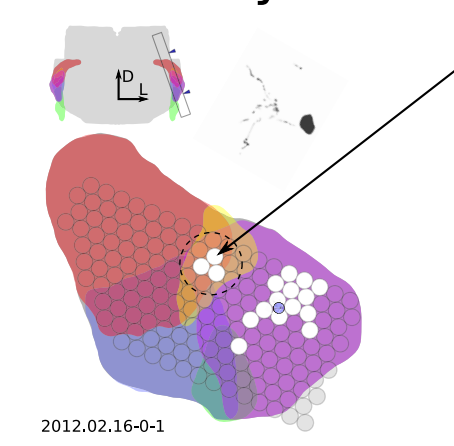

B Stellate

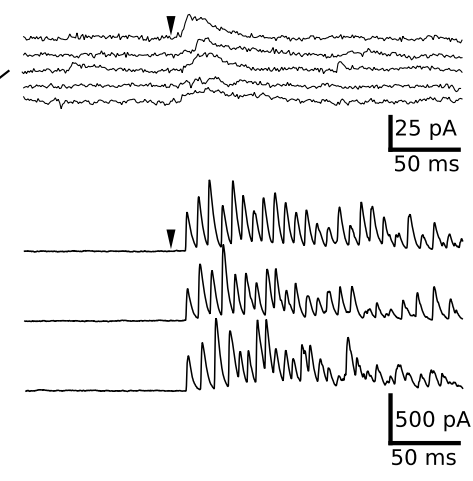

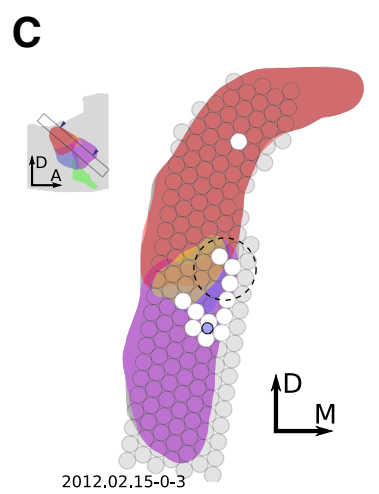
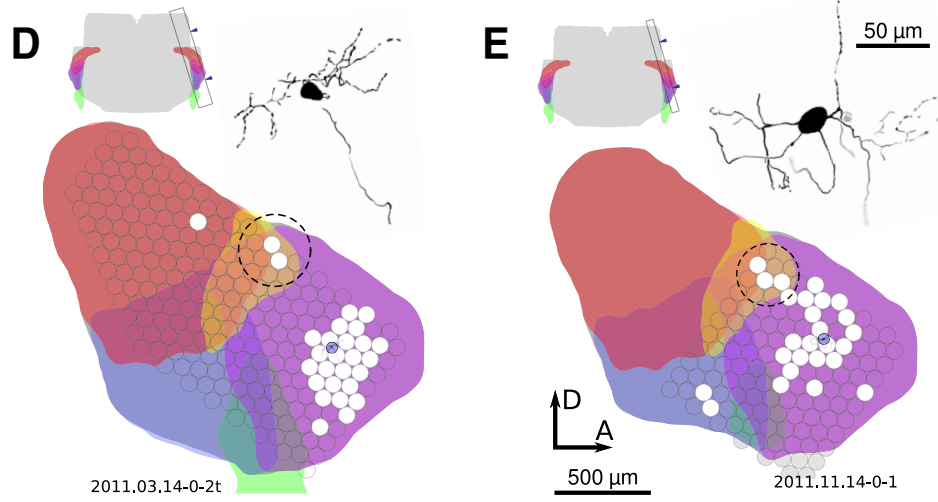

Figure 10. AVCN cells receive inhibitory input from the dorsal (D) and medial (M) borders of the AVCN. The format is described in Figure 6. Inputs at the dorsal and medial edge of the AVCN are indicated with a dashed circle. $\boldsymbol{A}$ and $\boldsymbol{C}$ are bushy cells, $\boldsymbol{B}$ and $\boldsymbol{E}$ are stellate cells, and the cell type in $\boldsymbol{D}$ is ambiguous. Morphology was not available for the cells in $\boldsymbol{B}$ and $\boldsymbol{C}$; their cell types were determined by physiological criteria. L, Lateral; $A$, anterior; $D$, dorsal; $M$, medial.

time constant of $4.2 \pm 1.0 \mathrm{~ms}(n=11)$, and DCN inhibition decayed with a time constant of $4.0 \pm 2.2 \mathrm{~ms}(n=5)$. ANOVA revealed a significant effect of target cell type $\left(F_{(1,53)}=55.1, p=\right.$ $\left.9.4 \times 10^{-10}\right)$, but no significant effect of inhibitory source $\left(F_{(2,53)}\right.$ $=1.81, p=0.17)$ or interaction between cell type and source $\left(F_{(2,53)}=2.86, p=0.066\right)$. Post-tests (Tukey's HSD) showed significant differences for all comparisons between bushy and stellate cells, regardless of source. Thus, the decay time constant for evoked IPSCs appears to be specific to the postsynaptic cell type and not to the inhibitory source.

The PSCs evoked by uncaging had a wide variety of amplitudes and temporal patterns, ranging from a detection limit of $\sim 10 \mathrm{pA}$ to hundreds of picoamperes. Some stimuli were followed by a single large IPSC, whereas others evoked long-lasting trains of IPSCs. The trains could exhibit a highly regular interevent interval, suggesting that only a single stimulated neuron was activated, or could show more complex patterns, suggesting that the events arose from multiple neurons. Despite this variability, we predicted that input strength might vary systematically depending on both the input region and the postsynaptic cell type. To test this, we measured the mean amplitude of events across stimulus sites within either the VCN or DCN that produced evoked responses in two time windows: from 3 to $20 \mathrm{~ms}$ and from 40 to $100 \mathrm{~ms}$ following stimulation (Fig. 13). The first window frequently contained the largest events, whereas the second window contained primarily smaller, isolated events that appeared to arise from presynaptic neurons firing long after the stimulus.

In both bushy and stellate cells, IPSCs evoked from within the VCN during the early $(0-20 \mathrm{~ms})$ window ranged from one to five times the amplitude of the spontaneous IPSCs in the same cells (Fig. 13C; VCN). This result indicates that photostimulation over the VCN evokes PSCs that are composed of multiple release events, due to convergence of inputs or greater quantal content from a single input. In bushy cells, IPSCs evoked from the DCN had similar amplitude to those evoked from the VCN. However, in stellate cells, events evoked by DCN stimulation were typically half the size of spontaneous events (Fig. 13C; DCN). Evoked synaptic events may be weaker than spontaneous events for a variety of reasons, such as differences between DCN and VCN inputs in intrinsic synaptic strength or dendritic filtering. However, it is not likely to result from rapid synaptic depression because IPSCs evoked by electrical stimulation of the DCN do not show strong depression at firing rates $<100 \mathrm{~Hz}$ (Xie and Manis, 2013). Whatever the mechanism, it appears that DCN inhibition onto stellate cells is particularly weak.

Because IPSCs evoked immediately after photostimulation are likely to be a superposition of multiple input events, we also measured the properties of events evoked in a later window, from 40 to $100 \mathrm{~ms}$ after photostimulation. These events are often well isolated and are likely to result from prolonged spiking in presynaptic neurons. In bushy cells, events evoked from VCN during the late window had the same amplitude as spontaneous IPSCs. In stellate cells, however, they were again smaller than spontaneous IPSCs (Fig. 13D; VCN). This suggests a greater inhibitory convergence from $\mathrm{VCN}$ onto stellate cells, compared with bushy cells. In contrast, events evoked from the DCN in the late window had similar amplitudes to events in the early window in both bushy and stellate cells (Fig. 13D; DCN), which suggests that convergence from DCN inputs is low in both bushy and stellate cells.

Together, our analysis of IPSC amplitudes shows that stellate cells, when compared with bushy cells, receive a greater convergence of inputs from the VCN and weaker inputs from the DCN. 

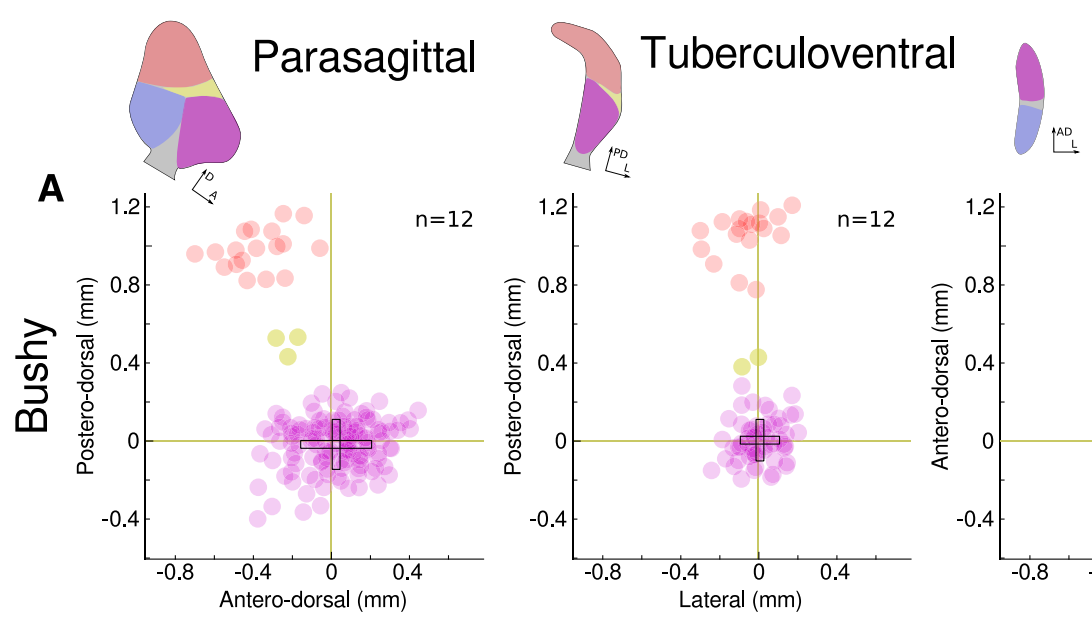

Ascending
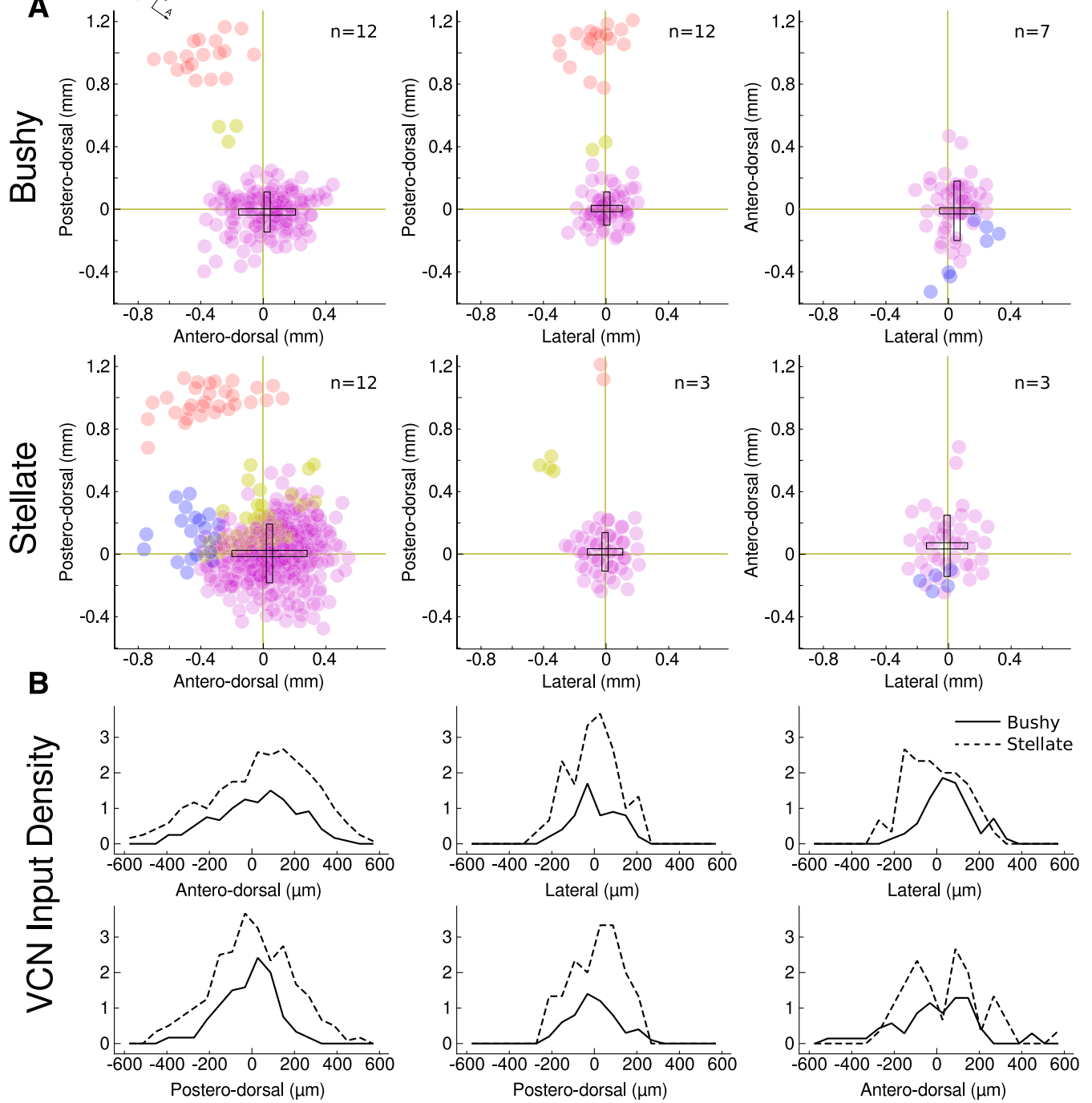

Figure 11. Combined maps and input density analysis of inhibitory connectivity. $A$, Cells were divided into groups based on cell type and slice plane, then maps were combined within groups and translated such that the postsynaptic cells all lie at the origin. Slice planes are described in Materials and Methods and Figure 1. Each spot indicates one detected input site from a single cell; colors indicate the anatomical region of the photostimulation site (green, AVCN; red, DCN; blue, PVCN; yellow, AVCN dorsal border). Black rectangles within the maps indicate the center and SD of the entire population of input sites for either VCN or DCN. The parasagittal slice plane is rotated such that the ascending branch of auditory nerve fibers is approximately parallel to the $x$-axis. $\boldsymbol{B}$, Each plot shows histograms of the average density of VCN input locations across the $x$-axis (top row) and $y$-axis (bottom row) from the maps above. The histograms are normalized by the number of cells in the group. Solid line, bushy cell; dashed line, stellate cell.

To further investigate this difference between bushy and stellate cells, we compared evoked IPSC amplitudes in cells that received input from both the VCN and DCN. This comparison confirmed that bushy cells trend toward stronger input from the DCN (Fig. $13 E$; geometric mean DCN/VCN ratio $=1.4$; one-sample $t$ test $\ln [\mathrm{DCN} / \mathrm{VCN}] \neq 0: t_{(7)}=1.82, p=0.1$ ), whereas stellate cells had significantly stronger input from the VCN (geometric mean $\mathrm{DCN} / \mathrm{VCN}$ ratio $=0.4$; one-sample $t$ test $\ln [\mathrm{DCN} / \mathrm{VCN}] \neq 0$ : $\left.t_{(5)}=3.92, p=0.011\right)$. Thus, the balance of inhibition between VCN and DCN sources depends on cell type; bushy cells have a weak preference for DCN inhibition, whereas stellate cells have a strong preference for VCN inhibition. The difference in DCN/ VCN ratio between the two cell types is statistically significant (permutation, $p<10^{-4}$ ), and may be the result of differences in convergence, intrinsic synaptic strength, or dendritic filtering.
Together, these results show that stellate and bushy cells have different patterns of local inhibitory connectivity that could support different information-processing capabilities. Compared with bushy cells, stellate cells receive a stronger, highconvergence inhibitory input from VCN sites. Conversely, bushy cells receive stronger inputs from DCN sites, although their total area of VCN inhibition is larger.

\section{Discussion}

We have mapped the synaptic connectivity of three anatomically distinct sources of inhibitory input and one source of excitatory input to AVCN neurons. While our results are largely consistent with previously published findings, we have extended these by providing estimates of the relative convergence and synaptic 

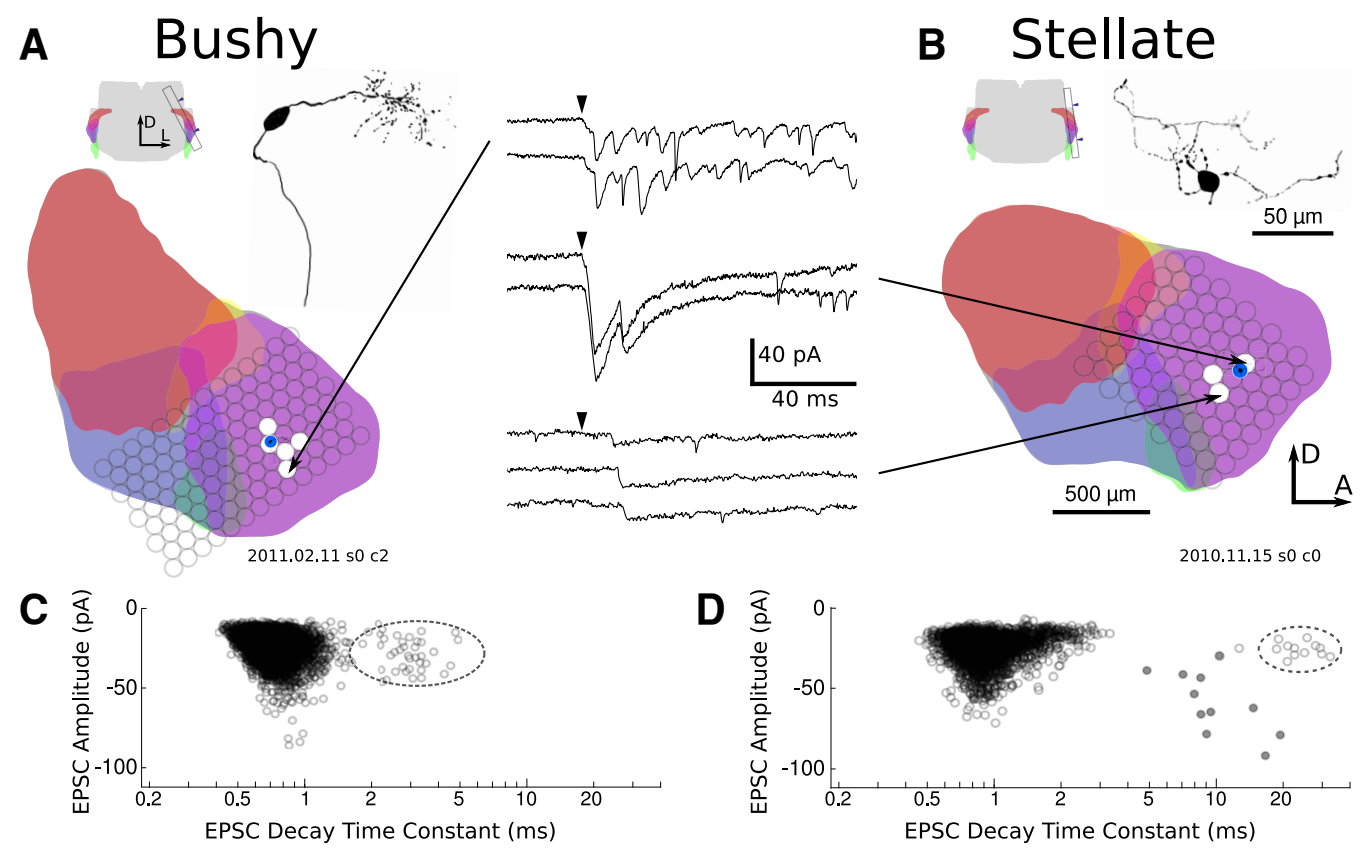

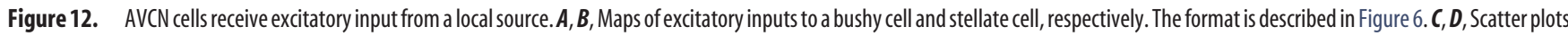
of events detected during all recordings for these cells. The circled regions include both spontaneous and evoked events that form a population with a slow decay time constant relative to the spontaneous release from auditory nerve fibers. The filled gray circles in $\boldsymbol{D}$ are direct stimulation responses. $D$, Dorsal; $L$, lateral; $A$, anterior.

properties between the various components of the AVCN circuit.

\section{Inhibition from the central VCN}

Strong but indirect evidence supports the hypothesis that glycinergic D-stellate cells in the VCN provide local inhibitory input to excitatory neurons. The collaterals of D-stellate axons branch profusely in the VCN (Arnott et al., 2004), and the terminals of these axons contain flattened and pleomorphic vesicles similar to those found in synapses on both bushy and stellate cells (Cant, 1981; Smith and Rhode, 1989; Ostapoff and Morest, 1991; Doucet et al., 1999). Furthermore, electrical stimulation of the auditory nerve root in VCN slices evokes delayed glycinergic inhibition in stellate cells (Wu and Oertel, 1987; Xie and Manis, 2013), even in the absence of the DCN (Ferragamo et al., 1998a). Lateral suppression areas are prominent in the frequency-response areas of both globular bushy and stellate neurons (Goldberg and Brownell, 1973; Shofner and Young, 1985; Smith and Rhode, 1989; Rhode and Greenberg, 1994; Palmer et al., 1996; Kopp-Scheinpflug et al., 2002). This suppression is thought to result primarily from inhibition from D-stellate cells because they have broad tonal response areas (Smith and Rhode, 1989; Palmer et al., 1996) and innervate cells across a broad frequency range within the AVCN (Arnott et al., 2004). Our results are consistent with the proposal that D-stellate neurons are a major source of local inhibition in the VCN.

We found that stellate cells consistently received inhibition from a greater area of the VCN than bushy cells, particularly along the axis orthogonal to the isofrequency sheets. Furthermore, the inhibitory events evoked from VCN sites were stronger in stellate cells than in bushy cells. Together, these results echo studies that have found stronger lateral suppression in the frequency-response areas of chopper units (T-stellate) than both primary-like (bushy) and onset chopper (D-stellate) units (Martin and Dickson, 1983; Smith and Rhode, 1989; Rhode and Greenberg, 1994). The strength and spatial extent of VCN inhi- bition onto stellate cells was highly variable, consistent with in vivo studies that have reported variability in the structure of the lateral suppression areas of VCN neurons (Evans and Nelson, 1973; Goldberg and Brownell, 1973; Brownell, 1975; Martin and Dickson, 1983; Paolini et al., 2005). Variability in the extent and strength of inhibitory input may contribute to the diversity of response properties among T-stellate cells (Palombi and Caspary, 1992; Ebert and Ostwald, 1995; Paolini et al., 2004, 2005; Gai and Carney, 2008).

Inhibition from D-stellate cells is thought to aid in the detection of narrowband signals masked by broadband noise (Palmer et al., 1996). For example, broadband inhibition by D-stellate cells is a candidate mechanism to underlie comodulation masking release (CMR; Hall et al., 1984), in which spectral and temporal cues are used to distinguish the signal from a broadband masker. Our observations have revealed that inhibition from the VCN to T-stellate cells is stronger and spectrally broader than to bushy cells, which may account for the greater sensitivity of stellate cells to CMR (Pressnitzer et al., 2001; Xie and Manis, 2013).

\section{Inhibition from the DCN}

Another source of inhibitory input comes from cells in the deep layer of the DCN that are presumed to be tuberculoventral neurons. We found that both bushy and stellate cells receive DCN input from a narrow band oriented parallel to the isofrequency sheets. This pattern agrees closely with previous anatomical and functional studies showing a precise tonotopic projection from DCN to VCN (Feng and Vater, 1985; Wickesberg and Oertel, 1988, 1990). Although the number of DCN stimulation sites providing input was the same for bushy and stellate cells, IPSCs evoked from the DCN were stronger in bushy cells than in stellate cells. Furthermore, IPSCs evoked from the DCN had a slower decay time constant in bushy cells than in stellate cells, which is in agreement with previous results (Xie and Manis, 2013). The differences in strength and time course of inhibition suggest that 


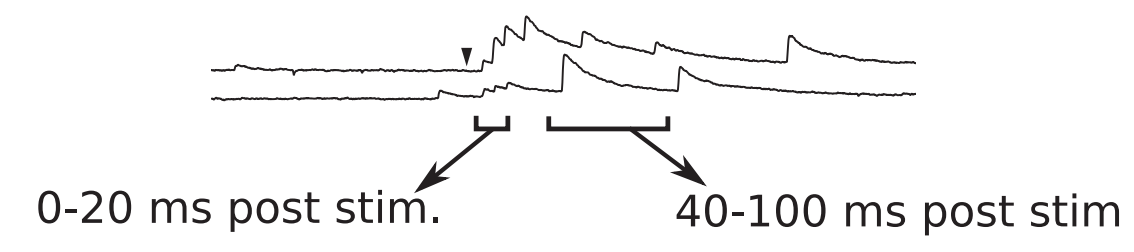

A
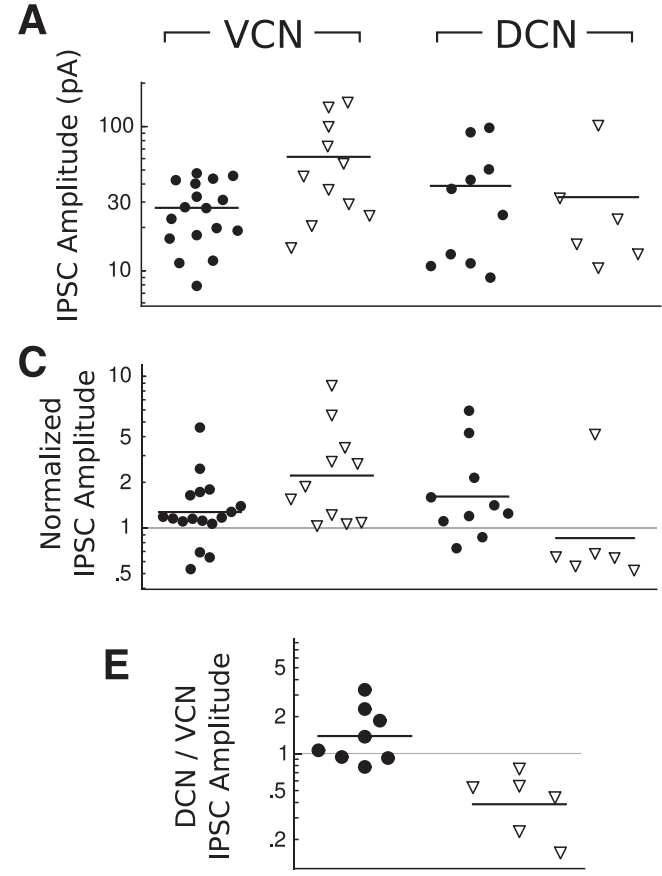

B

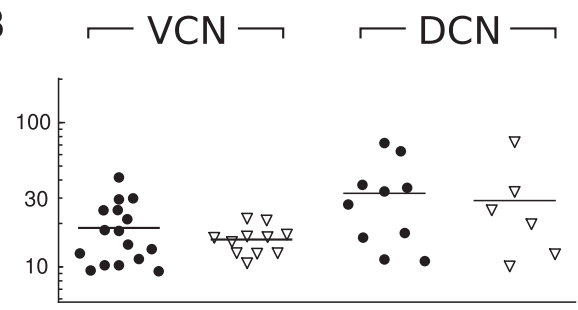

D
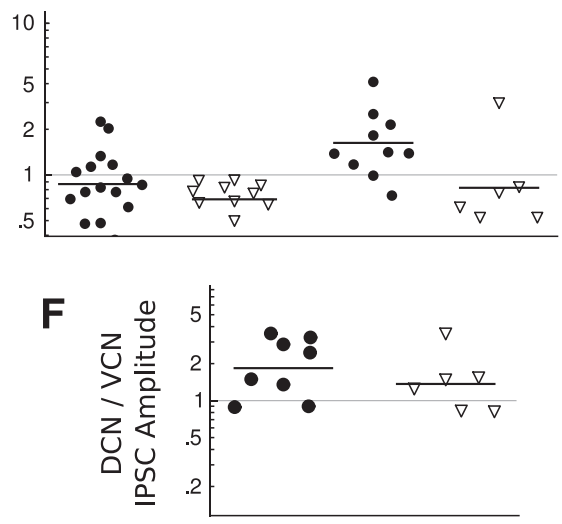

Figure 13. Evoked IPSC amplitude depends on both the input region and the target cell type. $A, B$, Evoked IPSC amplitudes for events of $0-20 \mathrm{~ms}$ and $40-100 \mathrm{~ms}$ poststimulus, respectively. $C$, $D$, Evoked IPSC amplitudes normalized by spontaneous IPSC amplitude per cell for the same time windows. $\boldsymbol{E}$, $\boldsymbol{F}$, Ratio of DCN/VCN IPSC amplitudes for the same time windows. In all plots, each symbol indicates the mean of event measurements for the specified time range, region, and cell type. Bars indicate means in $\boldsymbol{A}$ and $\boldsymbol{B}$; geometric means in $\boldsymbol{C} \boldsymbol{F}$.

tuberculoventral inhibition plays different roles in the two cell types.

Many functions have been proposed for tuberculoventral cells, including echo suppression, spike timing control, gain control, and dynamic range optimization (Wickesberg and Oertel, 1990; Caspary et al., 1994; Xie and Manis, 2013). Unlike D-stellate cells, tuberculoventral cells have narrow frequencyreceptive fields (Young and Brownell, 1976; Young and Voigt, 1982 ) and project to a tonotopically matched region in the VCN (Wickesberg and Oertel, 1988), and thus are unlikely to provide spectral contrast. In bushy cells, IPSCs from tuberculoventral cells are quite slow compared with auditory nerve inputs. This suggests that tuberculoventral cells may provide a temporal contrast that decreases the bushy cell response to slow fluctuations in the sound envelope, thus leaving greater dynamic range for representing fine temporal structure.

\section{Inhibition from the dorsal border of the AVCN}

We also identified a third source of inhibition evoked from sites at the dorsal and medial borders of the AVCN. This inhibition appears to arise from an anatomically distinct population of cells. Although some of these input sites appeared to reside entirely within the AVCN proper, sites close to the dorsal border could also have resulted from stimulation of the adjacent granule cell area. The source region was difficult to determine because of the limited spatial resolution of the photostimulation maps, and the overlap of anatomical regions that could be stimulated within the depth of the slice.
The two principal candidate sources for this inhibition are the marginal stellate cells (Doucet and Ryugo, 1997, 2006; Palmer et al., 2003) and commissural multipolar cells (Doucet and Ryugo, 2006). While it is not yet clear whether the marginal stellate cells are excitatory or inhibitory, the commissural cells are primarily inhibitory (Wenthold, 1987). Golgi cells, located in the granule cell area between the AVCN and DCN (Ferragamo et al., 1998b), are another candidate inhibitory source. However, because Golgi cell bodies and their axonal domains are largely restricted to the granule cell area, it is unlikely that they could account for the more medially located inputs seen in this study. Although some cells in this region are thought to participate in multisensory processing (Zhao et al., 1995; Zhou and Shore, 2004), the functional significance of these dorsal border inputs is not clear.

\section{Excitatory input from the VCN}

In $7 \%$ of cells, we detected excitatory inputs from an unknown cell type in the AVCN located close to the recorded cell. Neither bushy cells nor the granule cells covering the lateral surface of the AVCN have axonal projections into the AVCN, and so are unlikely to provide this excitation. In contrast, the axons of T-stellate cells have prominent collaterals in the VCN that terminate near the isofrequency lamina occupied by their dendrites (Oertel et al., 1990, 2011). These terminals contain small spherical (excitatory) vesicles (Smith and Rhode, 1989), which are similar to vesicles in nonprimary excitatory synapses on stellate and bushy cells (Cant, 1981; Smith and Rhode, 1987; Ostapoff and Morest, 1991). Ferragamo et al. (1998a) reported that $81 \%$ of the 
T-stellate cells in the PVCN had polysynaptic excitatory input following shocks to the auditory nerve, and suggested that the delayed excitation arose from nearby T-stellate cells. Although the excitatory inputs we observed could arise from T-stellate cell collaterals, the difference in the fraction of cells with input between our study and the Ferragamo et al. (1998a) study is striking, and suggests that there may be regional differences in the local excitatory networks formed by T-stellate cells in the AVCN and PVCN, or possibly strain differences between CBA and ICR mice. In addition, Gómez-Nieto and Rubio (2009) suggested that electrical coupling via gap junctions could provide local excitation among groups of bushy cells. We found no evidence for electrical coupling; however, a connection between adjacent bushy cells might be difficult to detect due to overlap of currents from electrical coupling and direct photostimulation.

We also observed that evoked EPSCs in bushy cells decayed about four times more slowly than spontaneous auditory nerve EPSCs. This result was further supported by the presence of similarly slow spontaneous EPSCs, even in some cells that had no evoked excitatory inputs. Whereas auditory nerve synapses onto bushy cells have exceptionally fast AMPARs that largely lack GluR2, stellate cells and DCN fusiform cells have AMPARs that include GluR2 subunits, giving them slower kinetics that are similar to the evoked EPSCs we have observed (Geiger et al., 1995; Ryugo and Parks, 2003; Cao and Oertel, 2010). Bushy cells do express GluR2, although at much lower levels than in other cell types (Hunter et al., 1993). Thus, it is possible that the kinetic differences between local excitatory and auditory nerve inputs result from different receptor subunit compositions.

The functional implications of the excitatory inputs we observed are unclear. Bushy cells are thought to precisely encode the fine temporal structure of sound, whereas T-stellate cells encode the sound envelope but not the fine temporal structure (Blackburn and Sachs, 1990; Frisina et al., 1990; Joris et al., 1994; White et al., 1994; Shofner, 1999). It is thus particularly surprising that some bushy cells have an excitatory input that would not seem to support fine timing. However, the spatial structure of the local excitatory inputs and the infrequency of slower EPSCs suggest that there may be a subtype of bushy cell that is more engaged with local excitatory circuits.

\section{References}

Arnott RH, Wallace MN, Shackleton TM, Palmer AR (2004) Onset neurones in the anteroventral cochlear nucleus project to the dorsal cochlear nucleus. J Assoc Res Otolaryngol 5:153-170. CrossRef Medline

Barbour DL, Callaway EM (2008) Excitatory local connections of superficial neurons in rat auditory cortex. J Neurosci 28:11174-11185. CrossRef Medline

Blackburn CC, Sachs MB (1989) Classification of unit types in the anteroventral cochlear nucleus: PST histograms and regularity analysis. J Neurophysiol 62:1303-1329. Medline

Blackburn CC, Sachs MB (1990) The representations of the steady-state vowel sound /e/ in the discharge patterns of cat anteroventral cochlear nucleus neurons. J Neurophysiol 63:1191-1212. Medline

Brownell WE (1975) Organization of the cat trapezoid body and the discharge characteristics of its fibers. Brain Res 94:413-433. CrossRef Medline

Cant NB (1981) The fine structure of two types of stellate cells in the anterior division of the anteroventral cochlear nucleus of the cat. Neuroscience 6:2643-2655. CrossRef Medline

Cant NB, Benson CG (2003) Parallel auditory pathways: projection patterns of the different neuronal populations in the dorsal and ventral cochlear nuclei. Brain Res Bull 60:457-474. CrossRef Medline

Cao XJ, Oertel D (2010) Auditory nerve fibers excite targets through synapses that vary in convergence, strength and short-term plasticity. J Neurophysiol 104:2308-2320. CrossRef Medline
Caspary DM, Backoff PM, Finlayson PG, Palombi PS (1994) Inhibitory inputs modulate discharge rate within frequency receptive fields of anteroventral cochlear nucleus neurons. J Neurophysiol 72:2124-2133. Medline

Chase SM, Young ED (2007) First-spike latency information in single neurons increases when referenced to population onset. Proc Natl Acad Sci U S A 104:5175-5180. CrossRef Medline

Doucet JR, Ryugo DK (1997) Projections from the ventral cochlear nucleus to the dorsal cochlear nucleus in rats. J Comp Neurol 385:245-264. CrossRef Medline

Doucet JR, Ryugo DK (2006) Structural and functional classes of multipolar cells in the ventral cochlear nucleus. Anat Rec A Discov Mol Cell Evol Biol 288:331-344. CrossRef Medline

Doucet JR, Ross AT, Gillespie MB, Ryugo DK (1999) Glycine immunoreactivity of multipolar neurons in the ventral cochlear nucleus which project to the dorsal cochlear nucleus. J Comp Neurol 408:515-531. CrossRef Medline

Ebert U, Ostwald J (1995) GABA alters the discharge pattern of chopper neurons in the rat ventral cochlear nucleus. Hear Res 91:160-166. CrossRef Medline

Evans EF, Nelson PG (1973) The responses of single neurones in the cochlear nucleus of the cat as a function of their location and the anaesthetic state. Exp Brain Res 17:402-427. Medline

Feng AS, Vater M (1985) Functional organization of the cochlear nucleus of rufous horseshoe bats (Rhinolophus rouxi): frequencies and internal connections are arranged in slabs. J Comp Neurol 235:529-553. CrossRef Medline

Ferragamo MJ, Golding NL, Oertel D (1998a) Synaptic inputs to stellate cells in the ventral cochlear nucleus. J Neurophysiol 79:51-63. Medline

Ferragamo MJ, Golding NL, Gardner SM, Oertel D (1998b) Golgi cells in the superficial granule cell domain overlying the ventral cochlear nucleus: morphology and electrophysiology in slices. J Comp Neurol 400:519528. CrossRef Medline

Frisina RD, Smith RL, Chamberlain SC (1990) Encoding of amplitude modulation in the gerbil cochlear nucleus: I. A hierarchy of enhancement. Hear Res 44:99-122. CrossRef Medline

Fujino K, Oertel D (2001) Cholinergic modulation of stellate cells in the mammalian ventral cochlear nucleus. J Neurosci 21:7372-7383. Medline

Gai Y, Carney LH (2008) Statistical analyses of temporal information in auditory brainstem responses to tones in noise: correlation index and spike-distance metric. J Assoc Res Otolaryngol 9:373-387. CrossRef Medline

Geiger JR, Melcher T, Koh DS, Sakmann B, Seeburg PH, Jonas P, Monyer H (1995) Relative abundance of subunit mRNAs determines gating and $\mathrm{Ca}^{2+}$ permeability of AMPA receptors in principal neurons and interneurons in rat CNS. Neuron 15:193-204. CrossRef Medline

Goldberg JM, Brownell WE (1973) Discharge characteristics of neurons in anteroventral and dorsal cochlear nuclei of cat. Brain Res 64:35-54. CrossRef Medline

Gómez-Nieto R, Rubio ME (2009) A bushy cell network in the rat ventral cochlear nucleus. J Comp Neurol 516:241-263. CrossRef Medline

Hall JW, Haggard MP, Fernandes MA (1984) Detection in noise by spectrotemporal pattern analysis. J Acoust Soc Am 76:50-56. CrossRef Medline

Hunter C, Petralia RS, Vu T, Wenthold RJ (1993) Expression of AMPAselective glutamate receptor subunits in morphologically defined neurons of the mammalian cochlear nucleus. J Neurosci 13:1932-1946. Medline

Jin X, Prince DA, Huguenard JR (2006) Enhanced excitatory synaptic connectivity in layer $\mathrm{v}$ pyramidal neurons of chronically injured epileptogenic neocortex in rats. J Neurosci 26:4891-4900. CrossRef Medline

Johnson GA, Badea A, Brandenburg J, Cofer G, Fubara B, Liu S, Nissanov J (2010) Waxholm space: an image-based reference for coordinating mouse brain research. Neuroimage 53:365-372. CrossRef Medline

Joris PX, Carney LH, Smith PH, Yin TC (1994) Enhancement of neural synchronization in the anteroventral cochlear nucleus. I. Responses to tones at the characteristic frequency. J Neurophysiol 71:1022-1036. Medline

Katz LC, Dalva MB (1994) Scanning laser photostimulation: a new approach for analyzing brain circuits. J Neurosci Methods 54:205-218. CrossRef Medline

Kopp-Scheinpflug C, Dehmel S, Dörrscheidt GJ, Rübsamen R (2002) Interaction of excitation and inhibition in anteroventral cochlear nucleus neurons that receive large endbulb synaptic endings. J Neurosci 22: 11004-11018. Medline 
Martin MR, Dickson JW (1983) Lateral inhibition in the anteroventral cochlear nucleus of the cat: a microiontophoretic study. Hear Res 9:35-41. CrossRef Medline

Muniak MA, Ryugo DK (2013) Tonotopic organization of vertical cells in the dorsal cochlear nucleus of the CBA/J mouse. J Comp Neurol. Advance online publication. Retrieved January 6, 2014. doi:10.1002/cne.23454. CrossRef Medline

Muniak MA, Rivas A, Montey KL, May BJ, Francis HW, Ryugo DK (2013) A 3-dimensional model of frequency representation in the cochlear nucleus of the CBA/J mouse. J Comp Neurol 521:1510-1532. CrossRef Medline

Oertel D (1983) Synaptic responses and electrical properties of cells in brain slices of the mouse anteroventral cochlear nucleus. J Neurosci 3:20432053. Medline

Oertel D, Wu SH, Garb MW, Dizack C (1990) Morphology and physiology of cells in slice preparations of the posteroventral cochlear nucleus of mice. J Comp Neurol 295:136-154. CrossRef Medline

Oertel D, Wright S, Cao XJ, Ferragamo M, Bal R (2011) The multiple functions of T stellate/multipolar/chopper cells in the ventral cochlear nucleus. Hear Res 276:61-69. CrossRef Medline

Ostapoff EM, Morest DK (1991) Synaptic organization of globular bushy cells in the ventral cochlear nucleus of the cat: a quantitative study. J Comp Neurol 314:598-613. CrossRef Medline

Ostapoff EM, Morest DK, Parham K (1999) Spatial organization of the reciprocal connections between the cat dorsal and anteroventral cochlear nuclei. Hear Res 130:75-93. CrossRef Medline

Palmer AR, Jiang D, Marshall DH (1996) Responses of ventral cochlear nucleus onset and chopper units as a function of signal bandwidth. J Neurophysiol 75:780-794. Medline

Palmer AR, Wallace MN, Arnott RH, Shackleton TM (2003) Morphology of physiologically characterised ventral cochlear nucleus stellate cells. Exp Brain Res 153:418-426. CrossRef Medline

Palombi PS, Caspary DM (1992) $\mathrm{GABA}_{\mathrm{A}}$ receptor antagonist bicuculline alters response properties of posteroventral cochlear nucleus neurons. J Neurophysiol 67:738-746. Medline

Paolini AG, Clarey JC, Needham K, Clark GM (2004) Fast inhibition alters first spike timing in auditory brainstem neurons. J Neurophysiol 92: 2615-2621. CrossRef Medline

Paolini AG, Clarey JC, Needham K, Clark GM (2005) Balanced inhibition and excitation underlies spike firing regularity in ventral cochlear nucleus chopper neurons. Eur J Neurosci 21:1236-1248. CrossRef Medline

Pressnitzer D, Meddis R, Delahaye R, Winter IM (2001) Physiological correlates of comodulation masking release in the mammalian ventral cochlear nucleus. J Neurosci 21:6377-6386. Medline

Raman IM, Trussell LO (1992) The kinetics of the response to glutamate and kainate in neurons of the avian cochlear nucleus. Neuron 9:173-186. CrossRef Medline

Rhode WS, Greenberg S (1994) Lateral suppression and inhibition in the cochlear nucleus of the cat. J Neurophysiol 71:493-514. Medline

Richardson MJ, Silberberg G (2008) Measurement and analysis of postsynaptic potentials using a novel voltage-deconvolution method. J Neurophysiol 99:1020-1031. CrossRef Medline

Rothman JS, Manis PB (2003a) Differential expression of three distinct potassium currents in the ventral cochlear nucleus. J Neurophysiol 89:30703082. CrossRef Medline

Rothman JS, Manis PB (2003b) The roles potassium currents play in regulating the electrical activity of ventral cochlear nucleus neurons. J Neurophysiol 89:3097-3113. CrossRef Medline

Ryugo DK, Parks TN (2003) Primary innervation of the avian and mammalian cochlear nucleus. Brain Res Bull 60:435-456. CrossRef Medline

Saint Marie RL, Benson CG, Ostapoff EM, Morest DK (1991) Glycine immunoreactive projections from the dorsal to the anteroventral cochlear nucleus. Hear Res 51:11-28. CrossRef Medline

Shepherd GM, Pologruto TA, Svoboda K (2003) Circuit analysis of experience-dependent plasticity in the developing rat barrel cortex. Neuron 38:277-289. CrossRef Medline

Shofner WP (1999) Responses of cochlear nucleus units in the chinchilla to iterated rippled noises: analysis of neural autocorrelograms. J Neurophysiol 81:2662-2674. Medline

Shofner WP, Young ED (1985) Excitatory/inhibitory response types in the cochlear nucleus: relationships to discharge patterns and responses to electrical stimulation of the auditory nerve. J Neurophysiol 54:917-939. Medline

Smith PH, Rhode WS (1987) Characterization of HRP-labeled globular bushy cells in the cat anteroventral cochlear nucleus. J Comp Neurol 266:360-375. CrossRef Medline

Smith PH, Rhode WS (1989) Structural and functional properties distinguish two types of multipolar cells in the ventral cochlear nucleus. J Comp Neurol 282:595-616. CrossRef Medline

Tanaka Y, Tanaka Y, Furuta T, Yanagawa Y, Kaneko T (2008) The effects of cutting solutions on the viability of GABAergic interneurons in cerebral cortical slices of adult mice. J Neurosci Methods 171:118-125. CrossRef Medline

Typlt M, Englitz B, Sonntag M, Dehmel S, Kopp-Scheinpflug C, Ruebsamen R (2012) Multidimensional characterization and differentiation of neurons in the anteroventral cochlear nucleus. PLoS One 7:e29965. CrossRef Medline

Webster DB, Trune DR (1982) Cochlear nuclear complex of mice. Am J Anat 163:103-130. CrossRef Medline

Wenthold RJ (1987) Evidence for a glycinergic pathway connecting the two cochlear nuclei: an immunocytochemical and retrograde transport study. Brain Res 415:183-187. CrossRef Medline

White JA, Young ED, Manis PB (1994) The electrotonic structure of regular-spiking neurons in the ventral cochlear nucleus may determine their response properties. J Neurophysiol 71:1774-1786. Medline

Wickesberg RE, Oertel D (1988) Tonotopic projection from the dorsal to the anteroventral cochlear nucleus of mice. J Comp Neurol 268:389-399. CrossRef Medline

Wickesberg RE, Oertel D (1990) Delayed, frequency-specific inhibition in the cochlear nuclei of mice: a mechanism for monaural echo suppression. J Neurosci 10:1762-1768. Medline

Wickesberg RE, Whitlon D, Oertel D (1991) Tuberculoventral neurons project to the multipolar cell area but not to the octopus cell area of the posteroventral cochlear nucleus. J Comp Neurol 313:457-468. CrossRef Medline

Wu SH, Oertel D (1984) Intracellular injection with horseradish peroxidase of physiologically characterized stellate and bushy cells in slices of mouse anteroventral cochlear nucleus. J Neurosci 4:1577-1588. Medline

Wu SH, Oertel D (1987) Maturation of synapses and electrical properties of cells in the cochlear nuclei. Hear Res 30:99-110. CrossRef Medline

Xie R, Manis PB (2013) Target-specific IPSC kinetics promote temporal processing in auditory parallel pathways. J Neurosci 33:1598-1614. CrossRef Medline

Young ED, Brownell WE (1976) Responses to tones and noise of single cells in dorsal cochlear nucleus of unanesthetized cats. J Neurophysiol 39:282300. Medline

Young ED, Voigt HF (1982) Response properties of type II and type III units in dorsal cochlear nucleus. Hear Res 6:153-169. CrossRef Medline

Zhao HB, Parham K, Ghoshal S, Kim DO (1995) Small neurons in the vestibular nerve root project to the marginal shell of the anteroventral cochlear nucleus in the cat. Brain Res 700:295-298. CrossRef Medline

Zhou J, Shore S (2004) Projections from the trigeminal nuclear complex to the cochlear nuclei: a retrograde and anterograde tracing study in the guinea pig. J Neurosci Res 78:901-907. CrossRef Medline

Zilany MS, Bruce IC, Nelson PC, Carney LH (2009) A phenomenological model of the synapse between the inner hair cell and auditory nerve: long-term adaptation with power-law dynamics. J Acoust Soc Am 126: 2390-2412. CrossRef Medline 